\title{
Physiological constraints and the transition to growth: implications for comparative development
}

\author{
Carl-Johan Dalgaard' · Jakob B. Madsen² $\cdot$ Holger Strulik ${ }^{3}$ (D)
}

Accepted: 23 June 2021 / Published online: 3 July 2021

(c) The Author(s) 2021

\begin{abstract}
It is a well known fact that economic development and distance to the equator are positively correlated variables in the world today. It is perhaps less well known that as recently as 1500 C.E. it was the other way around. The present paper provides a theory of why the 'latitude gradient' changed sign in the course of the last half millennium. In particular, we develop a dynamic model of economic and physiological development in which households decide upon the number and nutrition of their offspring. In this setting we demonstrate that relatively high metabolic costs of fertility, which may have emerged due to positive selection towards greater cold tolerance in locations away from the equator, would work to stifle economic development during pre-industrial times, yet allow for an early onset of sustained growth. As a result, the theory suggests a reversal of fortune whereby economic activity gradually shifts away from the equator in the process of long-term economic development. Our empirical results give supporting evidence for our hypothesis.
\end{abstract}

Keywords LONg-run growth · Evolution · Nutrition · Fertility $\cdot$ Education $\cdot$ Comparative development

JEL Classification $\mathrm{O} 11 \cdot \mathrm{I} 12 \cdot \mathrm{J} 13$

Holger Strulik

holger.strulik@wiwi.uni-goettingen.de

Carl-Johan Dalgaard

carl.johan.dalgaard@econ.ku.dk

Jakob B. Madsen

jakob.madsen@uwa.edu.au

1 Department of Economics, CAGE and CEPR, University of Copenhagen, Øster Farimagsgade 5, Building 26, 1353 Copenhagen, Denmark

2 Department of Economics, University of Western Australia, 35 Sterling Hwy, Crawley, WA 6009, Australia

3 Department of Economics, University of Goettingen, Platz der Goettinger Sieben 3, 37073 Göttingen, Germany 


\section{Introduction}

It is a well-known regularity that economic development tends to increase as one moves away from the equator. However, this state of affairs is of relatively recent origin. As shown below, in circa 1500, per capita income, proxied by population density, was negatively correlated with latitude across the world as well as within Europe; a result that was first noticed by Ashraf and Galor (2011). The objective of the present paper is to provide a theory that accounts for this remarkable 'reversal of fortune'.

This paper proposes that the intertemporally shifting latitude gradient is a consequence of differences in the physiological constraints faced by individuals at different geographical locations. The argument is anchored in an important fact from the fields of biology and physical anthropology: Individuals are inherently physically bigger (i.e., taller and heavier in terms of lean body mass) in locations further away from the equator. This phenomenon is labeled "Bergmann's rule" in the relevant literature, after Bergmann (1847). Bergmann's rule is possibly a consequence of positive selection towards greater cold tolerance in the aftermath of the exodus from Africa some 50,000 years ago, but it could potentially have other roots as well (see discussion below). The substantive implication of this "latitude gradient in body size" is that individuals living in colder climates would end up facing higher metabolic costs of fertility, on purely physiological grounds, since these costs are increasing in the body mass of the individual. As a consequence, during pre-industrial times we would expect progressively lower levels of population density the farther we move away from the equator (see Dalgaard \& Strulik, 2015). Moreover, if, in the pre-industrial era, technological change was positively influenced by population size, societies where citizens were bigger but less numerous would tend to be technologically less sophisticated, reinforcing the physiologically based reason for low economic development (see Aiyar et al., 2008; Ashraf \& Galor, 2011, for a formal discussion of the link between population density and technological change in a pre-industrial environment).

However, as technological change makes formal education more attractive, it is likely to be adopted sooner in societies where the relative costs of child quantity are greater; that is, places inhabited by bigger individuals, farther away from the equator. This is where the latitude-productivity nexus gradually begins its turnaround: As educational investments are undertaken, fertility declines and economic growth takes off. Consequently, the currently observed positive correlation between absolute latitude and development outcomes may be the product of a differentiated timing of the take-off, which provided places farther away from the equator with a developmental head start in the modern growth regime.

In support of this hypothesis, we develop a unified growth model and test its implications. The model features overlapping generations of children and adults. Adults are the economically active agents and decide on family size, the level of nutrition and schooling of the offspring as well as their own (luxury) consumption. Following Dalgaard and Strulik $(2015,2016)$ parents are subject to the physiological constraint that they have to cover their metabolic needs, which depend on their own body mass as well as the level of fertility. Moreover, body mass is transmitted via an intergenerational law of motion. Finally, a unique output good is produced using body size augmented labor, human capital, land, and technology.

The theory builds on three key elements. First, utility of parents is increasing in the quality and quantity of offspring as well as own consumption. There are two dimensions to child quality, which are assumed to be imperfect substitutes: nutrition and skill formation. Moreover, preferences are assumed to fulfill a 'hierarchy of needs' principle: In a 
time of crisis, parents will tend to adjust own (luxury) consumption more strongly than child quantity and quality. Second, the return to skill formation is increasing in the level of technological sophistication, and human capital production is non-convex. The latter element involves the assumption that parents costlessly transmit a minimum amount of skill to the next generation, which permits a corner solution in terms of skill investments when the level of technology is sufficiently low. Third, technology evolves endogenously and depends on human capital-augmented population size.

These elements interact in the following way. At early stages of development the economy finds itself in a 'Malthusian 'subsistence regime' featuring low income and a relatively poor state of technology. Consequently, parents only invest in child quantity and the nutrition-based quality component. As technology slowly advances, however, income rises gradually despite the resource diluting influence from population. Eventually, the economy transits into a 'post-Malthusian' regime. The higher level of income entices the parents to start spending resources on themselves; i.e., above and beyond subsistence requirements. In addition, parents choose to increase the size of the family further. Nutritional investments also rise, but not on a per child basis. Consequently, average body mass is not increasing despite a higher level of income. Yet as technology continues to advance, now at a higher pace, the economy ultimately moves into the 'sustained growth regime', where human capital investments are deemed optimal. As quality investments are intensified, individuals respond by lowering fertility, which also allows nutritional spending per child to increase, and growth takes off: economically and physiologically, in the sense of increasing body mass. In the long run, the economy converges to a steady state where fertility is at replacement level, average body mass and human capital investments are constant, and economic growth occurs at a constant rate.

We use our model to conduct experiments in order to examine the causes of the shifting latitude gradient described above. Specifically, we compare societies where individuals are inherently of different body size, which potentially could have been due to selection. Before the onset of the fertility transition, societies farther away from the equator spent more on child nutrition and less on child quantity. Due to smaller family size and lower population density, they developed fewer new technologies through learning by doing. The transition to modern growth arises when a critical level of technological sophistication is attained enticing individuals to commence human capital investments. This critical level of technology is declining in the average body size of individuals, since families with higher metabolic costs of fertility (child quantity) require less of an inducement to reduce fertility and to invest in child quality in the sense of human capital. Thus, societies farther away from the equator experienced the take-off to modern growth earlier and are richer today.

We test the implications of the model using pre-industrial and post-1800 data as follows. First, we show a reversal of fortune across the world as well as between the European countries anchored in the latitude gradient (Sect. 2). Second, using cross-country data, we examine the extent to which contemporary economic development is associated with height in 1900, while controlling for several factors that various authors have found to explain economic development, such as culture, institutions, and geographical characteristics (Sect. 6.1). Third, we use decennial data for Italian regions over the period 1821-2001 to test the implications of our model (Sect. 6.2). Fourth, we use annual panel data for the OECD countries over the period 1840-1980 to show that the fertility transition was triggered by foreign technological progress transmitted internationally through the trade channel and mediated through height (Sect. 6.3).

This paper is related to several strands of literature. On the theoretical side, the paper belongs to the literature on economic growth in the very long run (e.g., Galor \& Weil, 
2000; Galor \& Moav, 2002; Lucas, 2002; Cervellati \& Sunde, 2005; Strulik \& Weisdorf, 2008; De la Croix \& Licandro, 2013). It is also related to studies on evolutionary growth theory focussing on the geographically driven selection of biocultural traits, such as time preferences (Galor \& Özak, 2016) and loss aversion (Galor \& Savitskiy, 2018), see Ashraf et al. (2020) for a review. In particular, the model developed below uses elements from Dalgaard and Strulik $(2015,2016)$ who integrate nutrition, ontogenetic growth, and physiological constraints into theories of long-run economic development. While Dalgaard and Strulik (2015) focus on the impact of physiological constraints on the cross-country distribution of income and body size in Malthusian times, and Dalgaard and Strulik (2016) focus on the take-off of average body size after the fertility transition, we show here how physiological constraints can explain the differentiated take-off to growth and a reversal of fortune. ${ }^{1}$

We extend the theory of Dalgaard and Strulik $(2015,2016)$ by considering education as a second channel of child quality investments and by integrating it with the canonical model of unified growth theory (UGT). The key mechanism of UGT that explains the onset of the fertility transition, mass education, and the take-off from stagnation to modern growth is based on the interaction of advancing technological progress with the child quantity-quality trade-off: Parents start investing in child education and reduce fertility when technological progress increases the return to education sufficiently strongly (Galor $\&$ Weil, 2000). By integrating UGT with the physiological model of Dalgaard and Strulik $(2015,2016)$ we refine the predictions of UGT with respect to regional differences in the timing of the take-off. Specifically, the integrated model predicts that countries or regions populated by bigger people, ceteris paribus, initiate the fertility transition and the take-off to growth earlier. The reason is that child costs are higher for bigger children such that the quantity-quality trade-off with respect to education kicks in already at a (somewhat) lower level of the return to education. Thus, we argue that small differences in initial conditions with respect to underlying physiological constraints are powerful enough to generate the historically observed interregional reversals.

The paper is also related to existing contributions that have aimed to explain observed reversals of fortune in history (Acemoglu et al., 2002; Olsson \& Paik, 2016, 2020; Litina, 2016; Dalgaard et al., 2020). The present study differs from previous contributions on two fronts: First, we focus on the role played by absolute latitude, rather than other structural characteristics. Second, whereas previous work has focused on either institutional or cultural drivers of the reversal, the present study proposes a physiological mechanism. We elaborate on the value added of the present work in the next section.

The paper proceeds as follows. In the next section we document a series of stylized facts, regarding the interrelationship between geography, body mass and economic activity that we require the model to be able to account for. Section 3 develops the model, and

\footnotetext{
1 In a related work, Lagerlöf (2007) proposes an evolutionary economic theory of body size in the very long-run. The study focusses on an explanation of the hump shaped evolution of body mass before the Neolithic transition. It does not consider the evolution of body mass in modern times and how its dependence on geographic environments affect the timing of the take-off to sustained growth. Robson (2010) proposes a theory based on endogenous body size (somatic capital) in order to explain why individuals preferred to take up agriculture although it induced a deterioration of health and body size. Kaplan and Robson (2009) develop an evolutionary theory of body growth in order to explain the phenomenon of ageing. Dalgaard et al. (2021) extend the health deficit model of Dalgaard and Strulik (2014) with ontogenetic growth in utero and during childhood in order to explain fetal (or early-life) origins of health deficits in old age.
} 

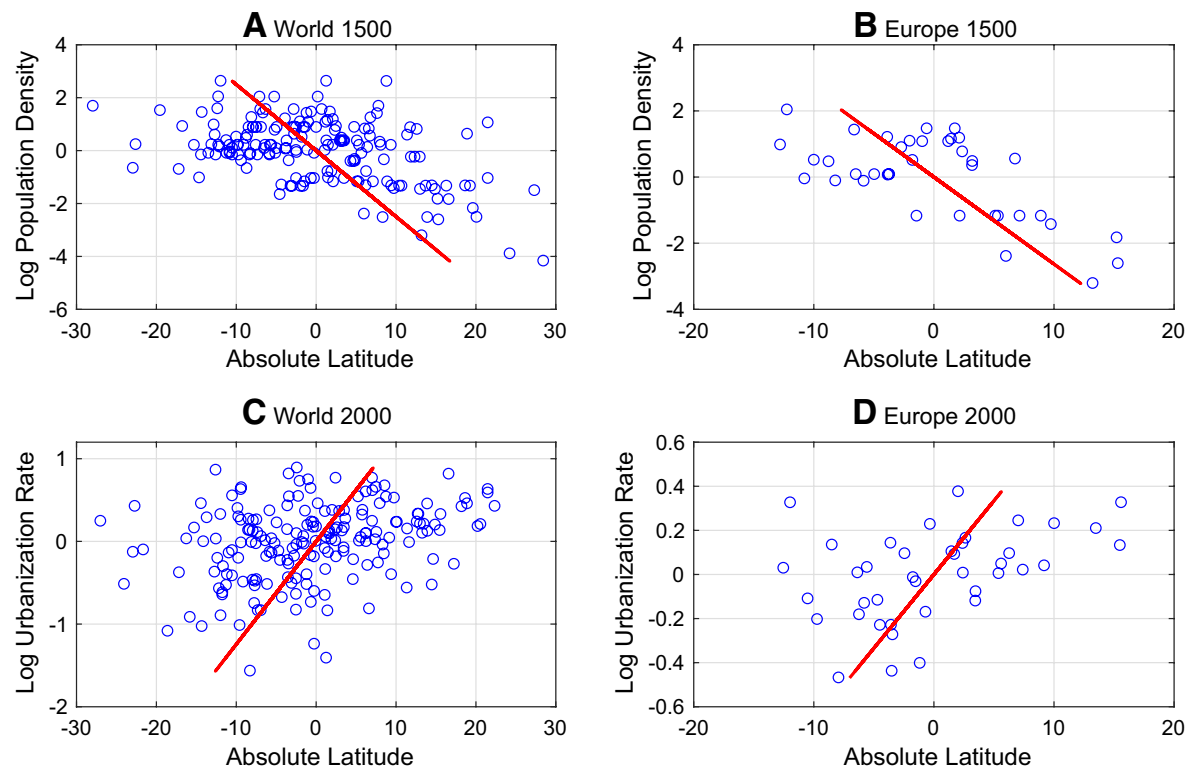

Fig. 1 The reversal of fortune. Panel A, B show the relationship between absolute latitude and population density in 1500 C.E. across the world and in Europe. Panel C, D show the relationship between absolute latitude and urbanization rates in the year 2000 across the world and in Europe. Continental fixed effects have been partialled out, i.e. latitude is measured relative to the continental mean. The depicted lines are estimated by OLS

Sects. 4 and 5 describe the development trajectory implied by the model. The empirics are presented in Sect. 6, and Sect. 7 concludes.

\section{Motivating evidence}

\subsection{The reversal re-examined}

In this section we present evidence for the reversal of fortune: Countries close to the equator reverted from being among the most developed in the world around 1500 to being among the least well-off in 2000. The reversal is illustrated in Fig. 1 Panels A and B show the association between absolute latitude and population density around 1500, approximating the state of development (Acemoglu et al., 2002; Ashraf \& Galor, 2011). As is visually obvious, economic development was negatively correlated with absolute latitude at the eve of the Age of Discovery. This association is found both across the world at large and within Europe. In Panels C. and D. we shift the focus to contemporaneous development, proxied by the urbanization rate (similar patterns emerge when we consider other indicators, such as GDP per capita). The latitude gradient turns to be positive at the level of the world at large and within Europe.

Table 1 shows the associated regression results. The first six columns show the link between absolute latitude and population density around 1500. We observe a significant negative correlation between absolute latitude and population density regardless of whether 


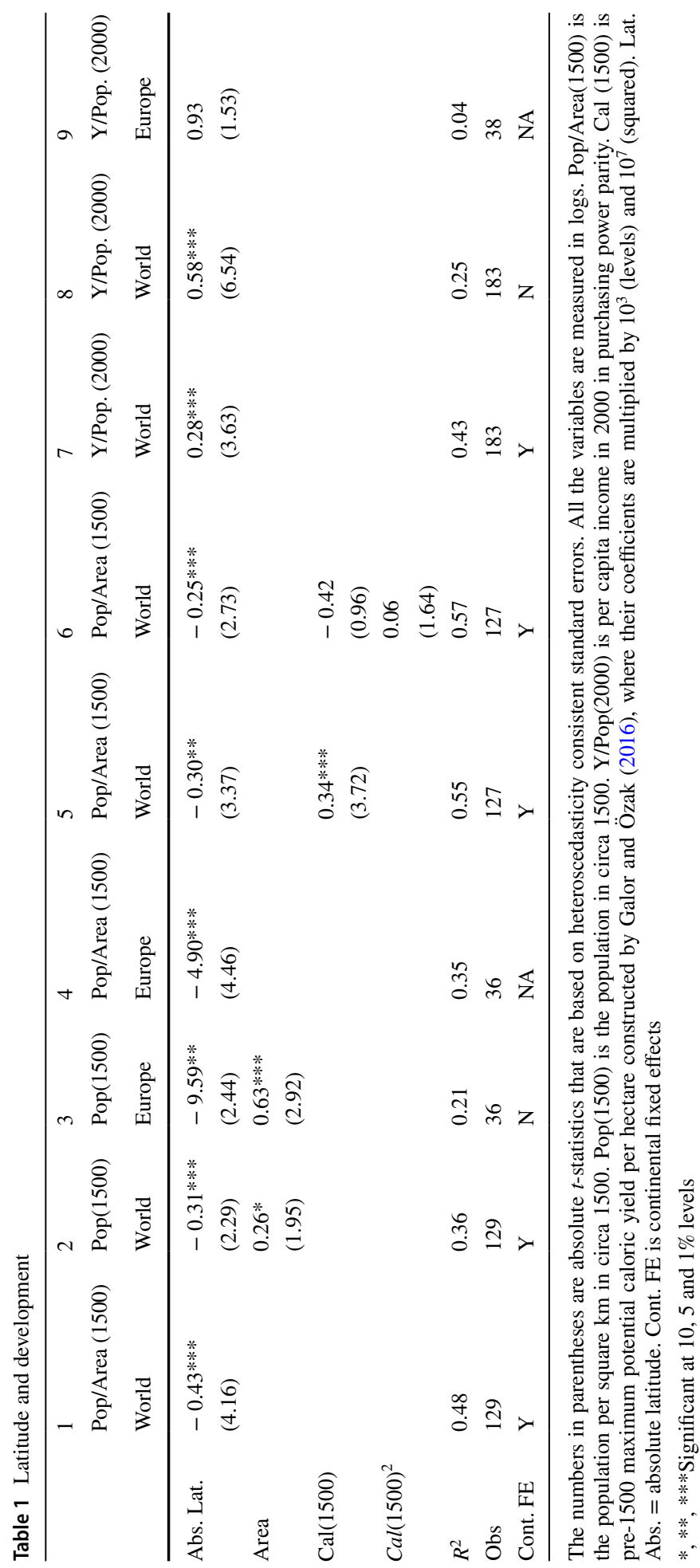


continental dummies are included in the models. Population density declines by about $4 \%$ when distance to the equator increases by $10 \%$ in latitude, implying that a move from Denmark to Greece increases population density by $131 \%$. The relationship between latitude and population density remains negative when the sample is limited to Europe (columns (3) and (4)). In column (5) we include pre-1500 maximum potential caloric yield per hectare in low-tech agriculture, $\mathrm{Cal}(1500)$, to control for the possibility that height may be affected by accessibility to food and, at the same time, that higher yields lead to higher population density; thus giving rise to an endogeneity bias because latitude captures factors other than the human surface area to volume ratio. The coefficient of calorie yield is significantly positive, while the coefficient of latitude remains significantly negative. In column (6), the squared caloric yield is added to the regression from column (5) to cater for the possibility that the caloric yield starts declining after a certain latitude is reached. The results in column (6) show that this not the case. If the level and square of calorie yield are unlogged, the level of caloric yield remains significantly positive, while squared caloric yield is significantly negative at the $1 \%$, level (the results are not shown). Although latitude remains significant at the $1 \%$ level the inclusion of the level and squared caloric yield as controls has changed the coefficient of latitude from -0.43 in column (1) to -0.25 in column (6). Finally, results from the modern era, which are reported in the last three columns in Table 1, show the well-known positive relationship between latitude and per capita income in year 2000. A move from Denmark to Greece is now associated with a 86-287\% decline in per capita income, depending on which result from Table 1 is adopted.

In light of the results from Table 1, the question is, what kind of mechanism may have driven this reversal. A classic account involves institutions. Acemoglu et al. (2002) observe a reversal of fortune across former colonies, arguing in favor of an institutional explanation. The argument is that places that were initially successful (measured by population density) were more likely to be characterized by extractive institutions imposed by the colonial powers, leading to a reversal in relative prosperity among former colonies. A natural question is whether institutions are implicitly responsible for the reversal of the latitude gradient.

The results in Table 1 show that the reversal of fortune also occurs within Europe, which suggests that extraction of rent from colonies with high settler mortality cannot be the only explanation for the reversal. More recent work by Olsson and Paik (2016, 2020) draws attention to a reversal involving the timing of the Neolithic revolution, whereas Litina (2016) and Dalgaard and Strulik (2016) observe a similar phenomenon related to soil suitability for agricultural production. Olsson and Paik $(2016,2020)$ argue that countries that underwent the Neolithic revolution relatively early developed extractive institutions and norms that emphasized obedience to the detriment of long-run growth. While an early Neolithic revolution allowed for a developmental head start, the cultural and institutional side effects eventually stifled development, allowing latecomers to sedentary agriculture to overtake. Litina (2016) argues that the reversal in soil quality can be explained by cultural change in favor of cooperative behavior in geographically "challenged" nations, eventually allowing them to industrialize comparatively early. Finally, Dalgaard and Strulik (2016) argue that rich inland soil productivity, relative to the productivity of the nearby ocean, led to less coastal orientation of economic activity early on, and thereby, to the accumulation of capabilities that were less favorable to industrialization. Accordingly, the common feature of this group of studies is a reliance on mechanisms that involve cultural change or an institutional mechanism.

A natural question is whether it is plausible that within country variations in body size (implicitly captured by absolute latitude) could influence within country long-run 
developments. Kelly et al. (2015) provide a fresh look at the determinants of the Industrial Revolution within two prominent European countries: England and France. In the case of England, the Industrial Revolution first took hold in the North, leading to a reversal of fortune since the South historically had access to richer agricultural lands. Empirically, the authors document that individuals in the North were physiologically relatively bigger than in the South. Kelly et al. (2015) explain the latter fact by persistent differences in the organization of production and a more nutritious diet. In the case of France, the authors also detect a significant link between body size and the timing of the Industrial Revolution. Moreover, people are indeed bigger, on average, in the Northern part of France. Hence, in the case of these forerunner countries of the Industrial Revolution, one observes differences in physiological development prior to the take-off that have predictive power visa-vis subsequent comparative regional development. In Sect. 6.2 we scrutinize the physiological explanation of the reversal of fortune across the regions of Italy.

\subsection{Geography and physiology}

In biology, Bergmann's rule (Bergmann, 1847) is a well established regularity with bearing on body size for (most) mammalian species. The rule states that the average body mass $(\mathrm{kg})$ of individuals is increasing in the distance to the equator. In the context of the human species, support is found in Gustafsson and Lindenfors (2009) among others. However, to have bearing on the reversal documented above, the latitude gradient needs to be apparent across countries and not just across indigenous societies, which has been the favored unit of analysis in the relevant empirical literature within physical anthropology. ${ }^{2}$

To investigate the nexus between body size and latitude, we regress height and body mass in the pre-1500 period against absolute latitude, with and without continental effects. The results are presented in the first four columns in Table 2. Consistent with Bergmann's rule, the coefficients of latitude are significantly positive in all cases.

To further examine the cross-country viability of Bergmann's rule, we employ height data for the population born in 1900, which cover a much larger cross-section of countries. Admittedly, data on body weight would be a more ideal measure but it does not appear to be available for this period. Hence, we use height as a proxy for body weight, exploiting the fact of a strong positive correlation between body weight and height. To show this for our pre-1500 sample, we regress body mass on the level and the square of height and obtain:

$$
B M(1500)=0.77(6.17) H(1500)+0.002(3.17) H(1500)^{2},
$$

where the numbers in parenthesis are $t$-values and $N=33$. The $R^{2}$ is 0.62 and Wald's $\chi^{2}$ (2) is 71.2, suggesting a strong positive relationship between body mass and height. Investigating the relationship between anthropometric measurements and climate, geographical

\footnotetext{
${ }^{2}$ As explained in Sect. 1, Bergmann's rule can be rationalized as a consequence of positive selection towards greater cold tolerance. With increasing body size the surface to volume ratio declines and thus bigger bodies radiate less heat per unit of mass. Alternatively, heat loss can be reduced by relative shortening of body extremities (arm and leg length) relative to trunk size. Allen's rule states that humans and other animals adapted to cold climates have shorter limbs relative to trunk size such that their bodies are more energy efficient and stay warmer (Allen, 1877). In our model, energy efficiency is captured in the equation of motion for body size by the parameter $d$, which is lower in colder environments. Because less energy is wasted via heat loss, bodies grow bigger in colder climates. Our model thus predicts that Allen's rule implies Bergmann's rule.
} 


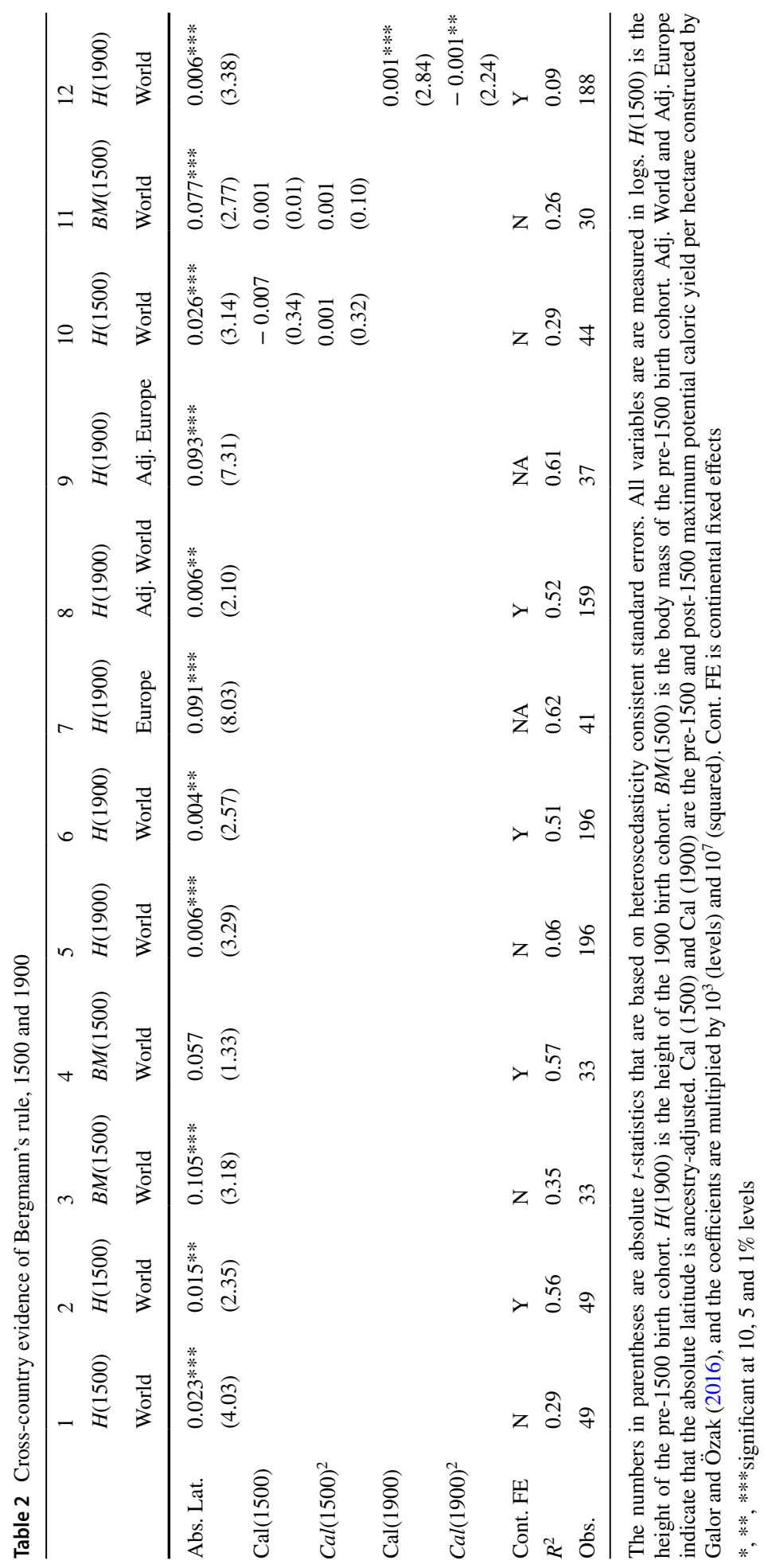


location, and linguistic affiliation of 62 groups of South American Indians, Stinson (1990) finds a significantly positive relationship between latitude, height and weight. Using a large cross-country sample of skeleton data, Cowgill et al. (2012) examine the variation in body proportions relative to latitude and climatic variables. They find that populations at higher latitudes are taller and more massive from the first year of life into maturity. Similarly, Tilkens et al. (2007) find a significant positive relationship between height and weight. In Sect. 6 (Table 4) we provide further evidence showing that indicators of contemporaneous development are similarly associated with weight and height in 1500 .

In Columns (5)-(7) of Table 2, we present the worldwide link between latitude and height in 1900, with and without continental effects. In all cases, body size is significantly positively correlated with absolute latitude across the world and within Europe. However, if the link between body size and latitude is generated by way of natural selection, these tests may not be ideal, since the post-Colombian period witnessed considerable international migration (Putterman \& Weil, 2010). As a result, the geographical location of people today does not necessarily reflect the geographical location of their ancestors. Hence, in order to control for the potential influence of post 1500 people flows, we examine the link between ancestor-adjusted absolute latitude and contemporary body mass. Evidently, places that today are inhabited by individuals with ancestors who lived far from the equator are characterized by greater average body mass than places inhabited by individuals with ancestors from locations closer to the equator. ${ }^{3}$ The results in which latitude is ancestoradjusted, are displayed in columns (8) (world) and (9) (Europe) in Table 2. The coefficients of ancestor-adjusted absolute latitude remain statistically highly significant and of similar size to the coefficients for unadjusted absolute latitude.

Finally, to control for the possibility that the size of the population is affected by land fertility, we include the level and the squared maximum potential caloric yield per hectare in low-tech agriculture in the pre-1500/post-1500 period as regressors in columns (10)-(12) in Table 2. The coefficients of the absolute latitude in the regressions with height in 1500 , body mass in 1500 and, height in 1900 as dependent variables, remain highly significantly positive; thus, giving further support to the Bergmann hypothesis. In the 1500-regressions, the coefficients of the level and the squared maximum caloric yield are insignificant, suggesting that the influence of body size for economic development is not driven by potential agricultural calorie yield. In agreement with the theory developed in Dalgaard and Strulik (2015, 2016), higher agricultural productivity in a Malthusian regime leads, in the long run, to greater population density (cf. Table 1) but not to bigger bodies.

Overall, the results reported in Table 2 complement the findings of Ruff (1994) and Gustafsson and Lindenfors (2009) of a positive latitude gradient in body size, in keeping with Bergmann's rule. The most common interpretation of this latitude gradient is that it emerged due to selective pressure whereby individuals with body characteristics that ensure greater cold tolerance have been positively selected in colder locations, in the aftermath of the exodus from Africa (e.g., Ruff, 1994; Katzmarzyk \& Leonard, 1998). The logic is, as a matter of geometric fact, that the surface area to volume ratio declines as body mass increases, which serves to reduce heat loss (see Ruff, 1994). Evidence of recent (i.e., over

\footnotetext{
${ }^{3}$ Ancestor-adjusted latitude for country $j$ is constructed as a weighted average of the absolute latitude of the country of origin of ancestors, Lat.Anc. $._{j}=\sum_{i=1} \lambda_{i} X_{i}$, where $\lambda$ is the contemporaneous population share with country $i$ ancestry, including that of country $j$, and $X_{i}$ is the absolute latitude of country $i$. The source of the international post 1500 migration matrix is Putterman and Weil (2010).
} 
the last 50,000 years) genetic selection towards greater cold tolerance in human populations is found in Hancock et al. (2010).

It is important to emphasize that our proposed theory does not hinge critically on any particular origin of a latitude gradient in body size. The theory remains relevant as long as absolute latitude predicts body size variation across countries regardless of the exact underlying reason. For example, if Bergmann's rule turns out to be caused by variation in disease load rather than evolutionary forces, this would not undermine the proposed physiological theory for the reversal of the latitude gradient.

\section{The model}

In this section we develop a unified growth model that can account for this set of facts, thereby providing a potential explanation for the reversal of the latitude-development gradient.

\subsection{Preferences}

Consider an economy populated by a measure $L_{t}$ of adult individuals, called households or parents. We abstract from gender differences such that any per capita variable can be thought of as being measured in per parent terms. Households derive utility from having children, spending on child quality, and from consuming non-food (luxury) goods.

As in Strulik and Weisdorf (2008) and Dalgaard and Strulik (2016), we assume that utility is quasi-linear. Non-food goods enter linearly, which makes them less essential and easier to postpone. This creates a simple device according to which consumption is restricted to subsistence needs when income is sufficiently low. The qualitative results would not change under a more general utility function as long as the elasticity of intertemporal substitution for child nutrition is smaller than for non-food (luxury) consumption.

Spending on child quality comes in two dimensions: nutrition and education. Following the anthropological literature (Kaplan, 1996) we assume that, from the preference side, there is no big difference between both of these quality components. Thus, both enter parental utility with the same weight. The most natural way to model this idea is to assume that both components are imperfect substitutes such that child quality (Becker, 1960) is given by the compound $c_{t} h_{t+1}$, in which $c_{t}$ is expenditure on child nutrition (approximating physiological quality) and $h_{t+1}$ is the human capital of the grown up child (approximating educational quality).

Summarizing, the simplest functional representation of utility is

$$
u=\log n_{t}+\gamma\left[\log c_{t} h_{t+1}\right]+\beta x_{t},
$$

in which $n_{t}$ is the number of offspring, $x_{t}$ is non-food consumption, and $\beta>0$ and $\gamma>0$ are the relative weights of non-food consumption and child quality in utility. We assume that $\gamma<1 / 2$ such that parents always want to have children and the constraint $n_{t} \geq 0$ never becomes binding with equality.

Parental child expenditure is driven by (impure) altruism, or the "warm glow", i.e., it is not instrumental; parents do not calculate how expenditure improves child productivity and future wages. Parents take into account how education improves the human capital of their children but not how nutrition affects body size. Given that humans invested in nutrition of 
their offspring long before they understood human physiology, this seems to be a plausible assumption. Moreover, at the steady state, the stock variable (body mass) is proportional to nutritional investments. Accordingly, in the long-run the two formulations will lead to similar steady-state results. ${ }^{4}$

Notice that, for simplicity, we did not include child mortality in the model. In the simplest case where dead children incur no costs, net fertility (as well as all other choice variables) are independent of child mortality (Galor, 2012). An impact of mortality on net fertility can be generated by assuming that all children consume nutrition but only surviving children receive education. If, additionally, child mortality then depends on latitude, there will be an independent influence of latitude on fertility as well as on all other choice variables. Thus, in the regressions below, we always check the robustness of the results when latitude is added as a control variable. ${ }^{5}$

\subsection{Technology}

Following Galor and Weil (2000) and Galor and Moav (2002), we assume that production takes place according to a constant returns to scale technology using the factors land $X$ and human capital $\tilde{H}_{t}$, such that aggregate output is

$$
Y_{t}=A_{t} \tilde{H}_{t}^{\alpha} X^{1-\alpha},
$$

in which $A_{t}$ is the endogenously determined level of technological knowledge at time $t$. Aggregate human capital is determined by the number of workers $L_{t}$ times their human capital $h_{t}$ times their physical capacity (muscle force), which scales with body mass $m_{t}$, such that $\tilde{H}_{t} \equiv m_{t}^{\tilde{\phi}} h_{t} L_{t}$. We denote human capital in the narrow sense, i.e., the aggregate productive knowledge incorporated in people, by $H_{t}$, where $H_{t}=h_{t} L_{t}$. Following conventional unified growth theory, we assume no property rights on land such that workers earn their average product, and income per capita is given by $y_{t} \equiv Y_{t} / L_{t}$. Normalizing land to unity we obtain

$$
y_{t}=A_{t} m_{t}^{\phi} h_{t}^{\alpha} L_{t}^{\alpha-1}
$$

in which $\phi \equiv \alpha \tilde{\phi}$. For simplicity, we focus on a one-sector economy such that output can be converted without cost into food and non-food.

The main motivation for adding body mass to the production function is that body mass matters for the amount of force the individual can muster; "brawn", in other words. Because muscle force is proportional to muscle cross-section area, measured in square meters, it rises with weight as $m^{2 / 3}$ (e.g., Astrand \& Rodahl, 1970; Markovic \& Jaric, 2004). Of course not all tasks in the production processes rely on 'brute force' to the same extent. Theoretical reasoning and empirical estimates in sport physiology suggest that individual performance in different tasks scales with body size as $m^{\phi}$, in which $\phi=2 / 3$ for exerting force (as, for example, plowing and digging), $\phi=0$ for moving and $\phi=-1 / 3$ for supporting body weight (Markovic

\footnotetext{
${ }^{4}$ Dalgaard and Strulik (2015) demonstrate that a "utility from body mass" model and a "utility from nutrition" model yield very similar results at the steady state. Yet the utility from body mass formulation is analytically considerably more cumbersome.

${ }^{5}$ In reality, child mortality and morbidity are likely to interact with nutrition and body size. Diseases increase the metabolic needs of sick children and parents may be induced to adjust nutrition to the survival prospects of their children (Strulik and Weisdorf, 2014).
} 
\& Jaric, 2004). In practice, one would then probably expect a positive exponent, which is bounded from above at $2 / 3$.

\subsection{Human capital}

Human capital production is a positive function of parental education expenditure per child $e_{t}$ and the level of knowledge that could potentially be learned at school $A_{t}$. Specifically we assume that

$$
h_{t+1}=v A_{t} e_{t}+\bar{h}, \quad 0<v \leq 1 .
$$

The parameter $v>0$ controls for the productivity of the education sector (or the share of productive knowledge that can be conveyed at school): The constant $\bar{h}$ denotes human capital picked up for free, for example, by observing parents and peers at work. The production function for human capital could be made more general at the cost of analytical inconvenience. The only crucial part is, as in Galor and Moav (2002), that the return on education is not infinite for the first unit of educational expenditure. This feature, generated by the assumption of some costless acquisition of human capital, produces a corner solution, i.e., the possibility that not investing in human capital is optimal in some environments. It allows us to capture the long epoch of stagnation where investment in formal education arguably did not take place (to a first approximation).

\subsection{Physiological constraints}

Parents are assumed to experience utility from consumption above subsistence needs $x_{t}$ but not from subsistence food consumption. Yet they have to eat to fuel their metabolism. The metabolic rate is endogenous and depends - as in Dalgaard and Strulik $(2015,2016)$ on body size and fertility. As elaborated by Kleiber (1932) and many studies since, energy requirements of non-pregnant humans scale with body size according to $\theta \cdot m^{b}$, with $b=3 / 4$; this parameter value has withstood empirical falsification for decades, and is consistent with theoretical priors, see Dalgaard and Strulik (2015) for more details. Moreover, rearing a child from conception to weaning increases the mother's metabolic needs by a factor $\rho$ (Prentice \& Whitehead, 1987; Sadurskis et al., 1988). This means that metabolic needs of an adult with $n_{t}$ children is given by $\left(1+\rho \cdot n_{t}\right) \theta m_{t}^{b}$. In order to convert energy into goods we employ the energy exchange rate $\epsilon$, which is measured in kilocalories per unit of a unique consumption good (see Dalgaard \& Strulik, 2015, for a more detailed elaboration of these physiological foundations). Total food expenditure of the family is thus given by adult food consumption including energy needs of children in utero and before weaning plus child food consumption after weaning times the number children, $C_{t}=\left(1+\rho n_{t}\right) \theta m_{t}^{b} / \epsilon+n_{t} c_{t}$ such that the parental budget constraint reads

$$
y_{t}=x_{t}+\left(c_{t}+e_{t}\right) n_{t}+\left(1+\rho n_{t}\right) \frac{\theta}{\epsilon} m_{t}^{b} .
$$


In order to construct the intergenerational law of motion for body size, we begin with the following energy conservation equation: ${ }^{6}$

$$
E_{t}^{c}=b_{c} N_{t}+e_{c}\left(N_{t+1}^{\prime}-N_{t}\right),
$$

in which $E_{t}^{c}$ is energy consumption during childhood after weaning (prior consumption is covered by adult metabolic needs), $N_{t}$ denotes the number of human cells after weaning, $N_{t+1}^{\prime}$ is the number of cells of the child as a grown up, $b_{c}$ is the metabolic energy a cell requires during childhood for maintenance and replacement, and $e_{c}$ is the energy required to create a new cell. Hence the left hand side is energy "input" and the right hand side captures energy use.

Observe that the conservation equation does not allow for heat loss. The extent of heat loss is thus implicit in the parameters; a human who manages greater heat loss can thus be seen as one featuring greater energy costs of cell maintenance and repair, i.e., a greater parameter value for $b_{c}$. As discussed in Sect. 2, there is good reason to believe that humans operating under different climatic circumstances are different in terms of cold tolerance, i.e., are different in terms of how effective the body is at releasing heat. Accordingly, a simple representation of acclimatization or genetic selection toward cold resistance would be that of a smaller value for $b_{c}$, implying less "wasted" energy expenditure due to heat loss. Less disease, which works to sap the individual of energy, would work in a similar way. Hence, in our simulations below we will allow $b_{c}$ to differ across countries and study how this affects the relative timing of the take-off and, thereby, comparative development, economically and physiologically.

The next step involves solving (6) for $N_{t+1}^{\prime}$ so as to obtain the number of cells of an adult as a function of the number of cells of a child after weaning and energy intake during childhood, i.e., by isolating $N_{t+1}^{\prime}$ in the equation above. We can further exploit the fact that the mass of a body is simply the mass of a cell $\bar{m}$ times the number of cells. This implies for the size of an adult that $m_{t+1}=\bar{m} N_{t+1}^{\prime}$. Moreover, using the fact that after weaning, the size of a child equals $\mu$ times the size of the mother (Charnov, 1991, 1993), we have $\bar{m} N_{t}=\mu m_{t}, 0<\mu<1 .^{7}$ This leaves us with:

$$
m_{t+1}=\frac{\bar{m}}{e_{c}} E_{t}^{c}+\left(1-\frac{b_{c}}{e_{c}}\right) \mu m_{t} .
$$

The intergenerational law of motion for body size has a simple interpretation: The size of the adult, $m_{t+1}$, is determined by energy consumption during childhood, $E_{t}^{c}$, plus initial size, $\mu m_{t}$, adjusted for energy needs during childhood, $-\left(b_{c} / e_{c}\right) \mu m_{t}$.

Given that $c_{t}$ denotes consumption of a child in terms of goods, total energy intake during childhood is $c_{t} \cdot \epsilon=E_{t}^{c}$, where $\epsilon$ converts units of goods into calories. Inserting this into (7) we obtain a law of motion for body size across generations:

\footnotetext{
${ }^{6}$ Implicitly, we draw on West et al.'s (2001) model of ontogenetic growth; see also Dalgaard and Strulik (2015).

7 A physiological justification for this assumption is that child development until weaning depends on energy consumption in utero and during the breastfeeding phase. Since bigger mothers consume absolutely more energy, the offspring should be larger at this point as it receives a fraction thereof. With this interpretation, the linearity should be seen as a simplification. It has no substantive implications for our main results if the linearity is relaxed, except for reduced tractability.
} 


$$
m_{t+1}=a \cdot \epsilon \cdot c_{t}+(1-d) \cdot \mu \cdot m_{t}
$$

in which $a \equiv \bar{m} / e_{c}$ and $d \equiv b_{c} / e_{c}$. It shows that the size of a grown up child correlates positively with the size of the mother. The "deep" physiological parameters $a>0$ and $0<d<1$ are given at the population level but may differ across populations, as observed above. In particular, we will allow $d$ (implicitly, $b_{c}$ ) to differ: $d$ will be assumed to be larger in locations closer to the equator, and smaller in places farther away from the equator where greater cold tolerance is assumed to prevail.

\subsection{Individual optimization}

Parents maximize (1) subject to (4) and (5) and non-negativity constraints on all variables. Let $\lambda$ denote the shadow price of income and let $B_{t} \equiv \theta \mathrm{m}_{t}^{b} / \epsilon$ denote the metabolic needs of a non-fertile adult in terms of goods. The first order conditions for utility maximum are:

$$
\begin{gathered}
0=(\beta-\lambda) \cdot x_{t} \\
0=1 / n_{t}-\lambda\left(c_{t}+e_{t}+\rho B_{t}\right) \\
0=\gamma / c_{t}-\lambda n_{t} \\
0=\left[\frac{\gamma v A_{t}}{v A_{t} e_{t}+\bar{h}}-\lambda n_{t}\right] \cdot e_{t} .
\end{gathered}
$$

Depending on the environment, the solution is assumed at the interior or at the corner where non-negativity constraints on education or on non-food consumption are binding with equality. As shown below, these solutions identify a 'sustained growth regime', a 'post-Malthusian regime”, and a 'Malthusian regime', respectively.

\subsection{Interior solution}

The interior solution of (9) is obtained as:

$$
\begin{gathered}
n_{t}=\frac{(1-2 \gamma) \nu A_{t}}{\beta\left(v A_{t} \rho B_{t}-\bar{h}\right)} \\
c_{t}=\frac{\gamma\left(v A_{t} \rho B_{t}-\bar{h}\right)}{v A_{t}(1-2 \gamma)} \\
e_{t}=\frac{\gamma \rho \nu A_{t} B_{t}-(1-\gamma) \bar{h}}{(1-2 \gamma) v A_{t}} \\
x_{t}=y_{t}-B_{t}-1 / \beta .
\end{gathered}
$$

A key result here is that education and nutrition are positively correlated. The result is intuitive. When the return on education increases because of increasing knowledge 
(increasing $A_{t}$ ), parents prefer to spend more on education and substitute child quantity for quality. The lower number of children reduces the total cost of child nutrition, to which parents respond by spending more on nutrition for each child.

Another important result is the trade-off between fertility and body size; since bigger mothers (with greater $B_{t}$ ) face greater metabolic costs of child rearing compared with smaller mothers, the result is intuitive. As seen below, this trade-off is obtained in all regimes, though the level of fertility and body size may vary. Empirically, there is strong support to be found in favor of a "size-number trade-off". Within biology the association is documented in, e.g., Charnov and Ernest (2006) and Walker et al. (2008), and in the context of human societies the inverse link between size and number of offspring is documented in, e.g., Hagen et al. (2006) and Silventoinen (2003); see Dalgaard and Strulik (2015) for a fuller discussion.

\subsection{Corner solution for education}

The post-Malthusian regime is defined by the feature that fertility is not yet declining but income is high enough to finance consumption above subsistence level.

Proposition 1 Parents do not invest in education when the level of knowledge $A_{t}$ is sufficiently low and thus the return on education is relatively low such that

$$
A_{t} \leq \bar{A} \equiv \frac{(1-\gamma) \bar{h}}{\nu \gamma \rho B_{t}} .
$$

The threshold $\bar{A}$ is declining in the weight of child quality in utility $(\gamma)$, the metabolic needs of adults $\left(B_{t}=\theta m_{t}^{b} / \epsilon\right)$, and the productivity of education $v$.

The proof solves (10c) for $e_{t}=0$. Notice that the threshold is more easily crossed when parents put more weight on child quality or when parents are bigger. The latter result occurs because children of bigger parents are more energy intensive, which causes parents to have fewer children and makes them more inclined to invest in their education.

The solutions at the post-Malthusian equilibrium (i.e., for $x_{t}>0$ and $e_{t}=0$ ) are

$$
\begin{gathered}
n_{t}=\frac{1-\gamma}{\beta \rho B_{t}} \equiv n_{t}^{x} \\
c_{t}=\frac{\gamma \rho B_{t}}{1-\gamma} \equiv c_{t}^{x} \\
x_{t}=y_{t}-B_{t}-1 / \beta .
\end{gathered}
$$

Notice that, in contrast to the interior equilibrium, the child quality-quantity decision is independent from knowledge.

\subsection{Corner solution for education and parental consumption}

It seems reasonable to assume that the broad population lived at subsistence level in most of their history. 
Proposition 2 Parents do not spend on non-food (luxury) consumption when

$$
A_{t} \leq \underline{A} \equiv \frac{B_{t}+1 / \beta}{m_{t}^{\phi} \bar{h} L_{t}^{\alpha-1}} .
$$

The proof solves (11c) for $y_{t} \leq 0$ and inserts (2). The result becomes immediately intuitive after noting from (11a) and (11b) that total child expenditure $c_{t} n_{t}$ is simply $1 / \beta$ at the post-Malthusian equilibrium.

The solution at the subsistence equilibrium $\left(e_{t}=x_{t}=0\right)$ is obtained as

$$
n_{t}=\frac{(1-\gamma)\left(y_{t}-B_{t}\right)}{\rho B_{t}} \equiv n_{t}^{s},
$$

and nutrition per child $c_{t}$ is the same as in (11b).

Proposition 3 Fertility at the subsistence equilibrium is increasing in income and declining in body size.

The proof follows from inspection of (12). This result was already obtained and extensively discussed by Dalgaard and Strulik (2015).

In principle, there exists a fourth equilibrium at which the education constraint is already relaxed $\left(e_{t}>0\right)$ while the subsistence constraint still binds with equality $\left(x_{t}=0\right)$. As shown in the "Appendix", at this equilibrium, nutrition and education are as in (10a) and (10b), while fertility is still increasing in income until the subsistence constraint is relaxed and the fertility transition sets in. Since the optimal condition for education is the same as for the interior solution, the education threshold remains the same as in Proposition 1 . This means that the main mechanism of the reversal of fortune, namely the feature that societies of bigger people cross the education threshold earlier, is preserved and qualitatively we obtain the same results, as discussed below. Empirically, the 'Malthus-cumEducation' regime is less appealing and in order to be brief, we neglect it here by assuming that parameters and initial values are such that the subsistence constraint is first relaxed when the level of technology advances, i.e., we assume that $\underline{A}<\bar{A}$.

\section{Macroeconomic dynamics and stages of development}

We next place the households into a macro economy. The size of the adult population evolves according to

$$
L_{t+1}=n_{t} L_{t}
$$

Following conventional unified growth theory (Galor \& Weil, 2000, and many other studies), we assume that knowledge creation is a positive function of education and population size. Denoting growth of knowledge by $g_{t+1}=\left(A_{t+1}-A_{t}\right) / A_{t}$, we thus assume

$$
g_{t+1}=g\left(e_{t}, L_{t}\right)
$$

with $\partial g / \partial e_{t}>0, \partial g / \partial L \geq 0$, and $\lim _{L \rightarrow \infty} g\left(e_{t}, L_{t}\right)$ bounded from above. The assumption that the effect of population size on $g$ is bounded means that there cannot be permanent long-run growth driven by population growth alone. It excludes the empirical unobserved 
case that technological progress generated by population growth overpowers the depressing effect of limited land such that the post-Malthusian economy explodes with forever rising population and rising rates of technological progress without the initiation of education.

\subsection{Body size and fertility in the three regimes}

In the Malthusian regime and the post-Malthusian equilibrium, optimal nutrition expenditure is given by $(11 \mathrm{~b})$, which is independent of the state of technology $A_{t}$. Inserting (11b) into (8) we obtain the law of motion for body size

$$
m_{t+1}=\frac{a \gamma \rho \theta m_{t}^{b}}{1-\gamma}+(1-d) \mu m_{t} .
$$

The fact that body size is determined simply by a differential equation for $m_{t}$, independent of the state of technology (and other dynamics variables), allows us to state the following result.

Proposition 4 In the the Malthusian subsistence equilibrium and the post-Malthusian equilibrium, body size converges towards the steady state

$$
m^{x}=m^{s}=\left(\frac{a \gamma \rho \theta}{(1-\gamma)[1-(1-d) \mu]}\right)^{1 /(1-b)} .
$$

The proof solves (15) for $m_{t+1}=m_{t}$ and shows that $0<\partial m_{t+1} / \partial m<1$ at $m^{s}$. Strictly speaking, we should call (16) a quasi-steady state, since technology is evolving. Thus, akin to the evolution of the economy in the standard unified growth model (Galor \& Weil, 2000), there exists a subsystem (here for body size) with steady-state convergence dynamics, while globally, the system continues to evolve due to technological progress. As long as the economy is in the subsistence regime or post-Malthusian regime, i.e., for $A_{t}<\bar{A}$, body size converges to (16). Once the threshold is crossed, body size evolves to the steady state body size that applies at the interior equilibrium.

Proposition 5 At the interior equilibrium, child nutrition, education, and fertility are independent of income. Education and nutrition are increasing functions of knowledge and fertility is a declining function of knowledge. With rising knowledge, education, nutrition, and fertility converge to the constants

$$
e^{*}=c^{*}=\frac{\gamma \rho \theta\left(m^{*}\right)^{b}}{\epsilon(1-2 \gamma)}, \quad n^{*}=\frac{\epsilon(1-2 \gamma)}{\beta \rho \theta\left(m^{*}\right)^{b}},
$$

and body size converges towards the constant

$$
m^{*}=\left(\frac{a \gamma \rho \theta}{(1-2 \gamma)[1-(1-d) \mu]}\right)^{1 /(1-b)} .
$$

The proof begins with assuming that $m_{t}$ converges towards a constant $m^{*}$ and concludes that consumption (10b) converges to $c^{*}$ for $A_{t} \rightarrow \infty$. Inserting $c^{*}$ into (8) and solving for the steady state at which $m_{t+1}=m_{t}$ provides the solution for $m^{*}$ and verifies the initial assumption that body size is constant. Inspection of (10) provides the results of comparative 
statics. Comparison of body sizes $m^{s}$ and $m^{*}$ in Propositions 4 and 5 verifies the following result.

Proposition 6 Ceteris paribus (i.e., for given parameters), individuals are bigger at the interior equilibrium than at the (quasi-) steady state of the subsistence equilibrium and the post-Malthusian equilibrium, i.e. $m^{*}>m^{s}=m^{x}$.

At any (quasi-) steady state we observe the following comparative statics.

Proposition 7 Ceteris paribus (i.e., for given other parameters), a smaller value for $d$ implies a greater body size at every (quasi-) steady state $m^{s}, m^{x}$, and $m^{*}$.

The proof follows from taking the derivative of $m^{j}$ with respect to $d, j \in\{s, x, *\}$. Hence, if, via selection or plasticity and acclimatization, the body shape of people changes to allow for less heat loss, and thereby greater cold tolerance, then the model predicts that such societies will also feature bigger people. We next compare fertility in the three regimes.

Proposition 8 Fertility is highest at the post-Malthusian (quasi-) steady state.

For the proof we first utilize the fact that body size is the same at the post-Malthusian steady state and Malthusian steady state such that $B_{t}$ is the same in (11a) and (12). Then, $n^{s}<n^{x}$ implies $1<\beta\left(y_{t}-B_{t}\right)$, which is true whenever the subsistence constraint binds. To see that $n^{*}<n^{x}$, insert $m^{s}$ into (11a), i.e., $n^{x}=\epsilon(1-\gamma) /\left[\beta \rho \theta\left(m^{s}\right)^{b}\right.$, and notice that $(1-2 \gamma)<(1-\gamma)$ and $m^{*}>m^{s}$.

\subsection{The transition towards modern growth}

Suppose that human history begins at a sufficiently low level of $A$ such that both the education constraint and the subsistence constraint are binding initially. Human economic and physiological development then runs through three distinct phases: a Malthusian regime, a Post-Malthusian regime and a sustained growth regime.

When $A_{t}$ is below the subsistence threshold $\underline{A}$ and the education threshold $\bar{A}$, no income is spent on non-food (luxury) consumption or on education, and all income gains are channeled to higher fertility. Body size in the Malthusian regime converges towards $m^{s}$. With output per capita gradually growing, the economy eventually surpasses the threshold $\underline{A}$ and enters the Post-Malthusian regime. People start enjoying utility from non-food (luxury) consumption. Fertility rises to a higher level (see Proposition 8) but food provision per child remains at subsistence level. This means that body size remains unchanged, $m^{x}=m^{s}$. With body size and thus metabolic needs $B_{t}$ fixed at (quasi-) steady state level, the threshold $\bar{A}$ is a constant. The threshold is lower in countries inhabited by bigger people and thus crossed at a lower level of knowledge $A_{t}$.

Once the threshold of the sustained growth regime has been crossed, parents start investing in the education of their children. This has a double effect on economic growth. Education increases the productivity of the current worker generation as well as, through knowledge improvements, the productivity of the next generation, which then invests even more in education such that the economy eventually converges to the steady state $e^{*}$. Along the transition to the steady state, fertility declines, which reduces the Malthusian pressure and leads to further increasing income. As a result, the economy takes off, enjoying 
accelerating growth rates. Eventually, economic growth stabilizes at a high plateau at the end of the fertility transition when education expenditure has reached its steady state.

With respect to education and fertility, the transition to the sustained growth regime is similar to the transition established in conventional unified growth theory (e.g. Galor $\&$ Weil, 2000). The present model additionally explains the physiological transformation of humans: with the take-off to growth, humans start getting bigger (Proposition 6). As explained above, the uptake of education and the entailed reduced fertility make spending on nutrition of children more desirable and, subsequently, the next generation of adults is bigger. The grandchildren are even bigger because there is a double effect: Grandchildren are born bigger because they are conceived by bigger mothers, and their parents spend more on nutrition because increasing knowledge increases their preference for child quality in both the education and nutrition dimension. Eventually, however, nutrition, and thus body size, converges to a constant (see Proposition 5).

\section{Physiological constraints and comparative economic development}

Consider two regions (or countries) named $A$ and $B$ that share all parameter values aside from the one for heat loss, $d$, which differs due to natural selection or plasticity and acclimatization. We assume that $d$ is lower in region $\mathrm{A}$ than in region $\mathrm{B}$. Consequently, humans are bigger in region $\mathrm{A}$.

\subsection{Analytical results}

In order to discuss the reversal of fortune analytically, we need two further assumptions on technology that will be relaxed in Sects. 5.2 and 5.3. First, we assume (akin to the analysis in Kremer, 1993), a knowledge production function (14) that creates new knowledge only occasionally such that fertility, according to (12), adjusts to the Malthusian steady state $(n=1)$ that prevails at the current level of technology. Second, we assume that the two regions share the same knowledge base. That is, technology is locally determined by population size (and when relevant: education) but the produced ideas spread instantaneously. Concretely, let $\tilde{A}_{t}^{j}$ denote the knowledge that has been created in region $j, j=A, B$. Knowledge available in region $j$, denoted by $A_{t}^{j}$, is given by

$$
A_{t}^{j}=\tilde{A}_{t}^{A}+\tilde{A}_{t}^{B}
$$

Proposition 9 Consider two regions that differ in the metabolic needs of adults determined by $d$ (heat loss) and are otherwise identical. Then the region with the smaller

(1) is inhabited by bigger individuals

(2) is less densely populated

(3) creates less knowledge in the Malthusian regime

(4) and enters the sustained growth regime earlier.

Result 1 follows from Proposition 7. In order to derive result 2 we compute the Malthusian steady state for a given level of technology $A_{t}=A$. To obtain steady state population 
density, we set $n_{t}=1$ in (12) and (13). Inserting (3) and (16) into (12) and solving $n_{t}=1$ for $L_{t}=L^{s}$ provides population density

$$
L^{s}=\left(\frac{\epsilon(1-\gamma) A \bar{h}}{\theta[\rho /(2-\gamma)]}\right)^{1-\alpha}\left(\frac{(1-\gamma)(1-d) \mu}{a \gamma \rho}\right)^{\frac{b-\phi}{1-\alpha}} .
$$

The comparative statics with respect to $d$ show that the region inhabited by bigger individuals is less densely populated at any given level of technology. Result 3 follows from applying the knowledge creation function (14) for each region. Result 4 follows from applying Result 1 and Proposition 1.

Proposition 9 rationalizes the reversal of fortune that we aimed to explain since we expect $d$ (i.e., cell maintenance costs $b_{c}$ ) to be inversely correlated with absolute latitude. These results reproduce the stylized facts listed in Sect. 2 when it is further recalled that an earlier take-off will yield an income gap between the two regions if observed at an appropriate point in time after the region inhabited by bigger people has taken off. Moreover, these results are quite intuitive. Relatively higher metabolic costs of fertility will, in the Malthusian era, work to lower fertility in places inhabited by physiologically bigger people. Lower fertility implies a lower population density and thus less creation of new knowledge since technological change is generated through learning-by-doing. ${ }^{8}$ However, the high metabolic costs of fertility and subsequent nutrition requirements of bigger children makes the region populated by bigger individuals more inclined to invest in education, and thus to substitute child quantity with quality. As a result, a lower critical level of technology is required for the fertility transition to take place. Consequently, an income gap emerges in favor of the region inhabited by physiologically bigger people. ${ }^{9}$

Notice that the theory does not predict that the response to changes in the environment for fertility or education is greater for bigger individuals. In fact, $\partial^{2} e_{t} /\left(\partial A_{t} \partial B\right)=0$, which can be verified from Eq. (10c), indicating that the partial strength of the response to technological change is independent of body size. Instead, the theory predicts that bigger individuals respond earlier with investment in education and reduced fertility to increasing technological sophistication of production (i.e., at a lower level of technology). These results are independent of the specification of the utility function $u(c, h, n)$ since they do not need any further assumptions on preferences beyond decreasing marginal returns. Intuitively, the threshold is crossed when, for the first time, the marginal utility derived from a unit of education equals the marginal utility of nutrition. Since parents of bigger children (who become bigger adults) spend more on nutrition, the marginal utility derived from nutrition is lower such that it is already equal to the marginal utility from education at a lower level of the return to education, i.e., at a lower level of technological sophistication.

\footnotetext{
${ }^{8}$ As in most of the related literature where technological progress is driven by learning-by-doing (e.g., Kremer, 1993; Galor \& Weil, 2000), we do not explicitly consider the distribution of the population within countries. Learning-by-doing may take place at greater intensity in cities and the notion would then be that more densely populated areas are also characterized by the presence of more and/or larger cities, which, in turn, generate more new knowledge. See Lucas (2009) for an approach to taking differences of rural and urban learning explicitly into account.

${ }^{9}$ Sustainability of long-run growth of income at a positive rate requires that $g\left(e^{*}, L_{t}\right)-(1-\alpha) n^{*}>0$. The reversal of fortune, however, is obtained irrespective of whether long-run growth is sustainable since it is based on the conditions that apply at entry into the modern era.
} 


\subsection{Comparative dynamics}

In order to illustrate the comparative dynamics, we use the parameterizations suggested in Dalgaard and Strulik (2015). Specifically, we set $b=3 / 4, \theta=70, \mu=0.15 ; \rho=0.2$, $\epsilon=0.28$ and, for the benchmark run, $d=0.5$. We set $\beta$ and $\gamma$ such that population growth peaks at $1.5 \%$ annually and fertility converges to replacement level at the modern steady state. This provides the estimates $\gamma=0.1$ and $\beta=0.0053$. We set $a$ such that the average body weight in Malthusian times is $60 \mathrm{~kg}$. This provides the estimate $a=1.65$. Region B (the region closer to the equator) is populated by individuals who share the same parameters except $d$, which is 0.8 . In region $\mathrm{B}$, average body weight is, therefore, $49.6 \mathrm{~kg}$ in the subsistence regime. We set $\alpha=0.8$ and $\phi=0.25$.

In this section we maintain the assumption of perfect knowledge sharing and relax the assumption of only occasional knowledge creation. Following Lagerlöf's (2006) parametrization of the Galor and Weil (2000) model, we assume knowledge created in region $j$ grows at rate

$$
g_{t+1}^{j}=\delta\left(e_{t}^{j}+\lambda\right) \cdot \min \left\{\left(L_{t}^{j}\right)^{\eta}, \Lambda\right\}
$$

We set the productivity parameters such that the model generates plausible growth rates during the Malthusian regime, the post-Malthusian regime, and the sustained growth regime. This leads to the estimates $\delta=0.05, \lambda=0.8$ and $\eta=0.3$. We set $\Lambda=2.5$.

Finally, we normalize $v=1$ and set $\bar{h}=1850$ such that region A experiences a century of almost constant high fertility rates before fertility begins to decline. After running the experiment we convert all variables into units per year using a period length of 30 years. We start the economies in the year 1000 and determine the initial population size and technology level such that region A enters the post-Malthusian regime in the year 1800 and the sustained growth regime in 1890 . The implied initial fertility rate is 1.106 and the implied population growth rate is $0.34 \%$. Region B shares the same initial technology and the same initial fertility rate, which means that it is more densely populated since people are smaller. The implied initial population ratio is $L_{0}^{B} / L_{0}^{A}=1.42$.

Figure 2 shows the implied trajectories for population growth, income growth, and body mass. Solid lines reflect the trajectories of region A and the dashed lines show region B. The time when the economies cross the thresholds $\underline{A}$ and $\bar{A}$ are indicated by vertical lines. The line style of the threshold crossing corresponds with the line style of the trajectories of country A and B. The bottom panel shows the relative stock of technologies invented in region A. The figure starts in the year 1600 because the years before 1600 look very much like 1600 (aside from population growth which is gradually increasing). Both regions share virtually the same population growth rate during the subsistence phase, implying that region $\mathrm{B}$ remains more populous than region A. Because of its larger size, region B produces more innovations; the innovation ratio $A^{A} / A^{B}=\left(L^{A} / L^{B}\right)^{\eta}$ is around 0.9 during the Malthusian phase and mildly falling.

In the year 1890, region A starts investing in education and initiates the fertility transition. Consequently, income growth takes off one period later, when the educated children enter the workforce and contribute to knowledge creation. In region $\mathrm{B}$, the take-off occurs two generations later. The technological leadership switches after the take-off of region A and the innovation ratio improves very quickly. In the year 1950 we observe, for the first time since the year 1000, that region A contributes more than region B to the worldwide stock of knowledge. From then on region A's relative contribution is increasing rapidly due 

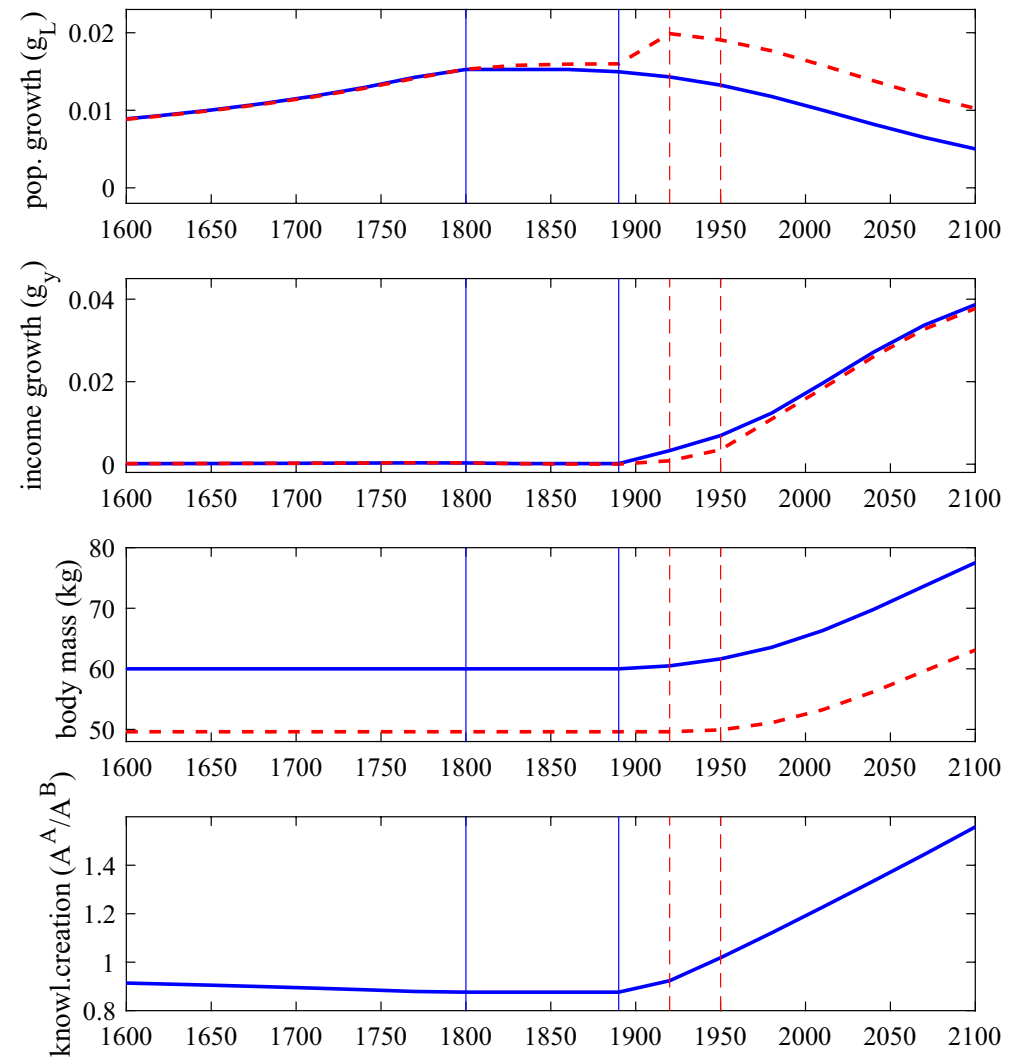

Fig. 2 Long-run comparative dynamics. Solid lines: region A $(d=0.5)$; dashed lines: region $\mathrm{B}(d=0.8)$. Vertical lines indicate threshold crossing, i.e. the entry into the post-Malthusian regime (threshold to the left) and the modern growth regime (threshold to the right)

to its better-educated workforce. After the take-off, A's average body weight is gradually increasing and reaches $65 \mathrm{~kg}$ in the year 2000 .

Region B benefits from the take-off of region A since the newly created knowledge diffuses freely. In region B, however, the resulting increasing productivity is initially used predominantly to further expand fertility because the region is still in its Malthusian regime and then briefly enters the post-Malthusian regime. Consequently, population growth increases further and approaches a high plateau in the first half of the twentieth century, while income growth is improving only very gradually. Then, in 1950, with a delay of two generations, region B invests in education, income takes off, population growth starts to decline, body size increases, and income growth converges to that of region A.

\subsection{Robustness: gradual diffusion and imperfect knowledge sharing}

The assumption of instantaneous diffusion of ideas is admittedly extreme and biases the results in the direction of an early take-off in societies that are inhabited by bigger but fewer people. In this section we explore how robust the reversal of fortune is when we allow for slow and incomplete diffusion of ideas. In assessing the results below it is 
important to recall the nature of the stylized fact in focus. We explore a mechanism that can potentially account for a reversal of fortune within continents, or even countries. As demonstrated in Sect. 2, the positive latitude-economic activity gradient holds when country fixed effects are partielled out. Whereas ideas surely traveled more slowly in pre-industrial times than today, the frictions in technology transfer that we have in mind do not refer to those between, say, China and Northern Europe, but rather to frictions in the diffusion of knowledge between Southern Europe and Northern Europe, or within China.

In order to allow for only partial and gradual diffusion of ideas, we replace (17) with

$$
A_{t}^{A}=\tilde{A}_{t}^{A}+\xi \tilde{A}_{t-k}^{B}, \quad A_{t}^{B}=\tilde{A}_{t}^{B}+\xi \tilde{A}_{t-k}^{A} .
$$

In the equation above, $\xi$ captures the fraction of ideas that (asymptotically) can be diffused. Hence, $\xi<1$ means that some ideas are never diffused. Furthermore, the equation above captures that new ideas arrive in the non-innovating countries with a delay of $k$ generations. Aside from these novel elements, we keep the structure of the model unchanged, along with the parameter values discussed above.

The initial value of technologies available in each region is adjusted such that both countries initially share the same fertility rate (as in the benchmark run). This implies that the initial technologies created in each region are given by $\tilde{A}_{0}^{A}=\left(A_{0}^{A}-\xi A_{0}^{B}\right) /\left(1-\xi^{2}\right)$ and $\tilde{A}_{0}^{B}=\left(A_{0}^{B}-\xi A_{0}^{A}\right) /\left(1-\xi^{2}\right)$. We adjust the initial value of population size such that region $\mathrm{A}$ experiences the take-off in 1870 and the outcome is comparable with Fig. 2.

Figure 3 shows results for $\xi=1$ and $k=2$, i.e., for a 60 year delay in international knowledge diffusion. Interestingly, and perhaps surprisingly, the delayed knowledge flow does not delay the take-off of region $\mathrm{B}$. The reason is that imperfect knowledge flows also operate during Malthusian times, during which region B is the technological leader. Imperfect knowledge flows thus reduce the speed at which region A reaches the threshold $\bar{A}$. The difference compared to the development in Fig. 2 is mainly that delayed knowledge flows reduce the catch up speed of region $B$ after its take-off.

More generally, we can use the model and ask the question: For which delay in international knowledge diffusion does the result of the earlier take-off of region A break down? The results are summarized in Table 3 .

If all knowledge is usable in all countries $(\xi=1)$, then region A takes off first up to a diffusion lag of 12 generations (360 years). The maximum diffusion lag decreases as we reduce the degree of international knowledge sharing. If only $60 \%$ of knowledge is transferable internationally, region A takes off earlier for up to a diffusion lag of 5 generations (150 years). If $20 \%$ or less of the knowledge is shared internationally, region A fails to take off earlier.

We experimented with different numerical specifications of the model and found generally that region A takes off one to two generations earlier and that this result is robust to substantial impediments to knowledge diffusion. Usually we can allow for delays of ten or more generations when all knowledge is shared across regions (i.e., within continents or countries) and up to $50 \%$ interregional knowledge sharing when the diffusion delay is 3 generations or less. The theoretical result of the reversal of fortune, which we could prove only for perfect knowledge sharing, appears to be robust to substantial imperfections in interregional knowledge sharing.

The testable implications of the theory are that countries or regions inhabited by bigger individuals were less densely populated before the onset of the fertility transition, experienced the fertility transition earlier, and are richer and better educated today. Another testable implication of the theory is a refinement of standard unified 

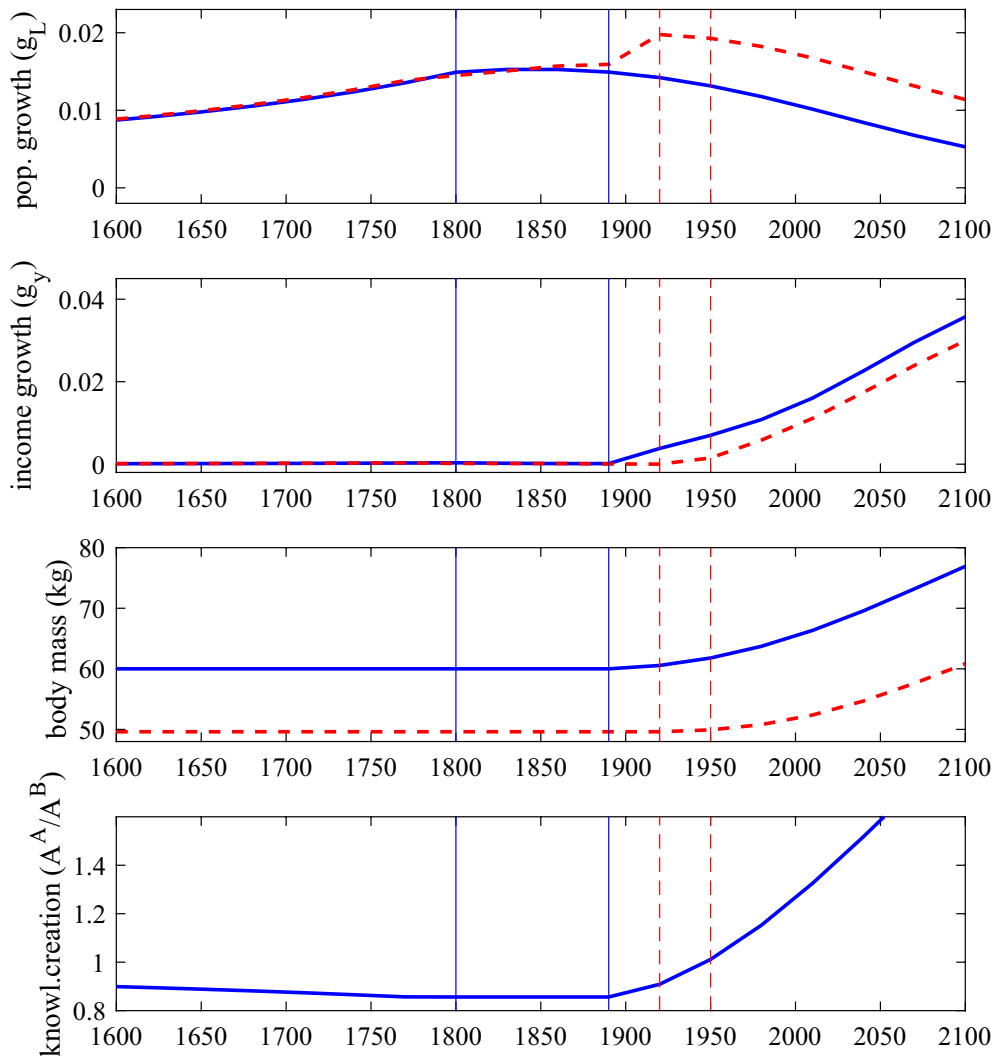

Fig. 3 Long-run comparative dynamics: gradual diffusion of ideas. Parameters as for Fig. 2 but knowledge diffuses with a lag: knowledge created in one region at time $t$ reaches the other region at time $t-2$

Table 3 Robustness checks: Knowledge diffusion

\begin{tabular}{llllll}
\hline$\xi$ & 1 & 0.8 & 0.6 & 0.4 & 0.2 \\
$k$ & 12 & 9 & 5 & 2 & - \\
\hline
\end{tabular}

The table shows, for alternative degrees of international knowledge sharing $\xi$, up to which diffusion lag (in terms of generations) the result that the initially backward region A takes off first continues to hold

growth theory (UGT), in which technological advances increase the return to education and, if sufficiently strong, induce an increase in education and a reduction of fertility (Galor \& Weil, 2000). Our theory proposes that the UGT mechanism is mediated by body size, i.e., that countries populated by bigger individuals respond to technological progress earlier (and thus, at any given time after the onset of the fertility transition, more strongly) with reduced fertility. 


\section{Empirical estimates}

In this section we show that height has been a significant determinant of economic development across time and space, where we focus on the three proxies for economic development: the fertility transition, per capita income, and education. To show this, we present three modules of estimates in this section: (1) cross-country regressions using pre-1500 height and body mass as regressors; (2) cross-country regressions using height in 1900 as regressor; and (3) panel regressions for the Italian regions over the period 1821-2001 in which long lags of height are employed as regressors. Finally, we carry out panel regressions for 18 OECD countries over the period 1840-1980 to examine whether the effect of technological change on fertility reductions is mediated by height. The data are discussed in each subsequent section, summary statistics are presented in online Appendix A3, and the data sources are listed in online Appendix A4.

\subsection{Reduced form predictions: cross-country estimates}

The following regressions are carried out using the sample pertaining to height and weight in 1500 and height in 1900:

$$
\begin{gathered}
\log \text { FTran }_{i}=\alpha_{0}+\alpha_{1} \log X(\text { Year })_{i}+Z_{i} \zeta^{\prime}+\epsilon_{1, i}, \\
\log Y(2000)_{i}=\beta_{0}+\beta_{1} \log X(\text { Year })_{i}+Z_{i} \xi^{\prime}+\epsilon_{2, i}, \\
\log E d u(2000)_{i}=\gamma_{0}+\gamma_{1} \log X(\text { Year })_{i}+Z_{i} \tau^{\prime}+\epsilon_{3, i},
\end{gathered}
$$

where Year is alternatively 1500 and $1900, X=H$ when the anthropometric measure is average male height, and $X=B M$ when it is body mass (weight). FTran is the year of the onset of the fertility transition (where we use the years computed by Reher (2004); extended with missing countries as documented in the online Appendix). Reher (2004) estimates the year of the fertility transition as the beginning of the first quinquennium (five-year period) after a peak during which the fertility rate declines by at least $8 \%$ over two quinquennia and never returns to the levels that prevailed at the first transitional year. $Y(2000)$ is per capita income in purchasing power parity in $2000 ; E d u(2000)$ is educational attainment (years of education) of the adult population in 2000; $Z$ is a vector of control variables; $\epsilon$ is a disturbance term; and subscript $i$ refers to country $i$. All variables, including the control variables, are in logs to dampen the leverage of extreme observations.

In the $B M(1500)$ and the $H(1500)$ regressions we only control for latitude, maximum caloric yield, and continental fixed effects because the limited number of observations constrains the room for maneuver. In the $H(1900)$ regressions, we control additionally for variables that are potentially correlated with height, such as cultural factors, institutional factors, health insults and geographic characteristics. The coefficients of height and weight are expected to be positive in the models for per capita income and educational attainment and negative in the model for fertility transition, as bigger bodies trigger an earlier fertility transition. 


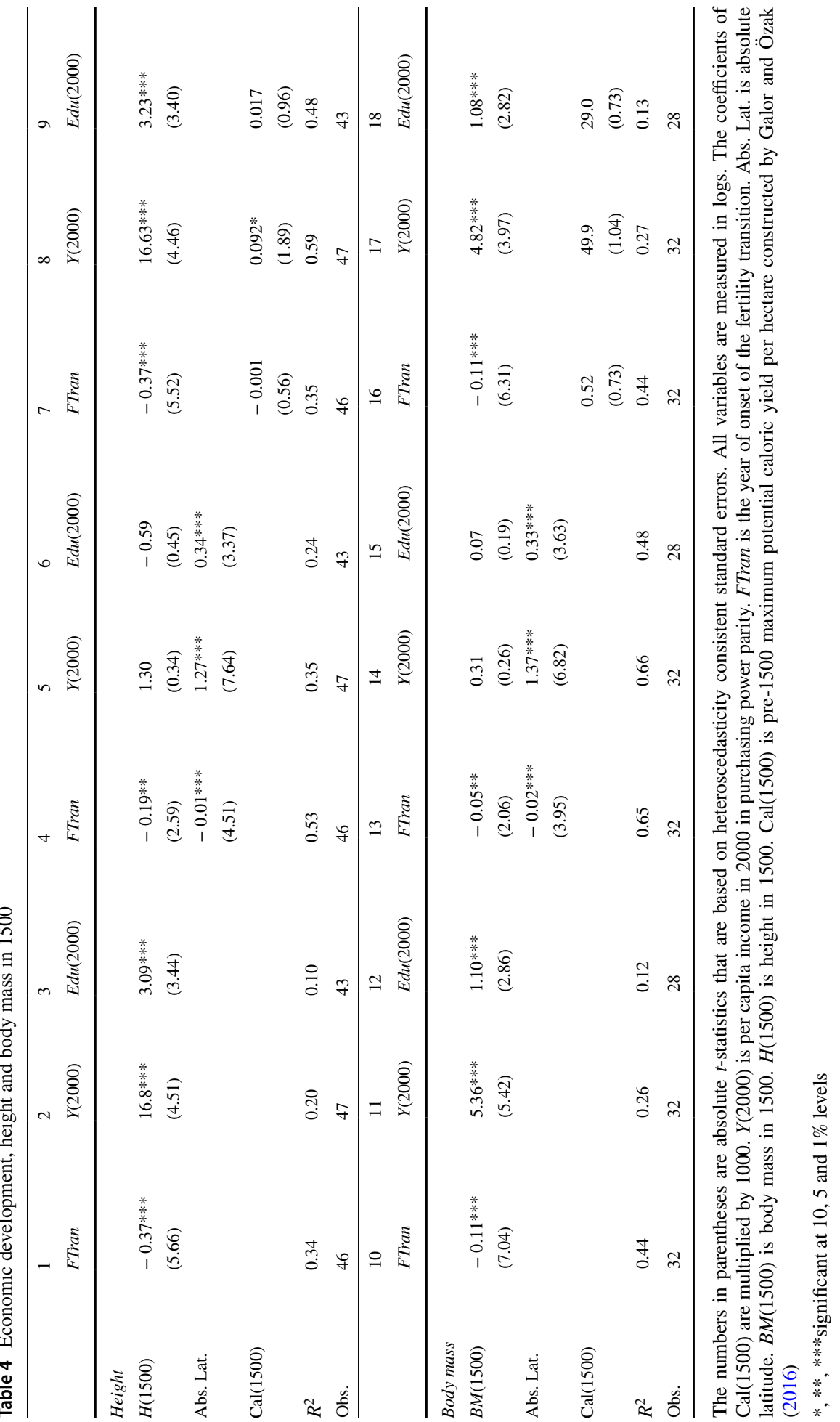




\subsubsection{Evidence using pre-1500 body mass and height}

In this sub-section we use height and weight data, mostly dated in the period 1300-1500, which we have collected from a large number of sources as detailed in the online Appendix. The data are archaeological evidence from samples of excavations and, as such, are only approximately representative for the population that lived in the entire country at that time. This is particularly true for countries with a large diverse population ancestry.

The results of estimating (21)-(23) are shown in Table 4. Consider first the estimates in the three first columns from the left in Table 4 (columns (1)-(3) for height and columns (10)-(12) for weight). The coefficients of height and body mass are significant at the $1 \%$ level and have the expected signs in all cases. ${ }^{10}$ Another noticeable feature of the estimates is that the principal results are quite similar for body mass and height; thus, corroborating the analysis in Sect. 2 that height is an excellent proxy for body mass.

To check the robustness of baseline results, we include latitude, as it is widely acknowledged that economies farther away from the equator are more successful in terms of economic development, while countries close to the equator have a higher prevalence of disease, highly variable rainfall and inferior soil quality (Gallup et al., 1999). Furthermore, we include the pre-1500 maximum potential caloric yield per hectare that is constructed by Galor and Özak (2016). This variable provides the potential calories that one could get from low-tech agriculture and, therefore, controls for the possibility that height and weight are partly a result of the accessibility of food. When latitude is included in the regressions, the coefficients of height and weight are rendered insignificant at the 5\% level in the models in which income or educational attainment in the year 2000 are the outcome variables, while they are significantly negative in the fertility regressions (columns (4) and (13)). Since per capita income and education in 2000 are outcomes of a myriad of factors where height is just one of them, the insignificance of the anthropometric measures in these two regressions is not so surprising. Furthermore, as argued below in Sect. 6.1.2, measured education is likely an imperfect proxy for human capital. Of importance is the significance of body mass and height in the fertility transition regressions, particularly because fertility is the key outcome variable explained by our theory. Finally, the size and significance of the coefficients of height and body mass is hardly affected by the inclusion of maximum potential caloric yield (see columns (7)-(9) and (16)-(18)).

Another plausible reason for the insignificance of anthropometric measures when latitude is included in the income or education regressions is that absolute latitude is positively correlated with measurement errors in the weight and height data. Consider, for example, height. Regressing height in 1900 on height in 1500 yields a coefficient of height in 1500 of $0.52(t=4.36)$, while the reverse regression yields a coefficient of $0.63(t=5.21), \mathrm{N}$ $=47$, which, unsurprisingly, suggests that the measured height in 1900 is a more reliable

\footnotetext{
${ }^{10}$ It may be helpful to relate the results in Table 4 to the earlier results discussed in Dalgaard and Strulik (2016). There, a negative association between the year of the fertility transition and contemporaneous body size is established. A quantity-quality trade-off explains why, after the onset of the fertility transition, later born offspring are taller and heavier. Here, we argue that countries that were populated by taller people (long) before the fertility transition, initiated the fertility transition earlier and are thus richer and better educated today. In other words, the study of Dalgaard and Strulik (2016) focused on within country developments and a causality running from the timing of the fertility transition to contemporaneous body size, while causality in this study runs from historical body size to the timing of the fertility transition across countries.
} 
measure of the population height than measured height in 1500 (all variables are measured in $\operatorname{logs}$ and latitude is controlled for, see for reliability tests, Krueger and Lindahl 2001). More importantly, in these regressions the coefficient of absolute latitude is significantly positive at the $1 \%$ level when $H(1500)$ is the regressor, but insignificant in the regression in which $H(1900)$ is the regressor. These results suggest that latitude is likely to be correlated with the measurement error of height in 1500 and, therefore, that the parameter estimates of height (and weight) in 1500 are downward biased when latitude is included as regressor.

Turning to economic significance based on the results in columns (1)-(3) in Table 4, suppose that the average height of a Filipino of $156 \mathrm{~cm}$ in the pre- 1500 period was equal to the height of the sample average of $166 \mathrm{~cm}$, where the Philippines had the shortest population in our sample in 1500. Then, the Philippines would have experienced the fertility transition in 1906 instead of 1955. Furthermore, their per capita income and educational attainment would have been $110 \%$ and $33 \%$ higher in 2000 compared with the actual outcomes (the height elasticity of educational attainment is estimated from the sample average of 8.47 years of education in 2000). In the other extreme, if the average height of a Norwegian was $156 \mathrm{~cm}$ as opposed to the actual average height of $173.6 \mathrm{~cm}$, Norway would have experienced a fertility transition in 1974 instead of the actual year of 1905 .

\subsubsection{Cross-country evidence over the last two centuries}

In this section we regress the outcome variables on height in approximately 1900 and a set of prominent variables that are used in the literature to explain economic development. While the availability and quality of the outcome variables in the year 2000 are well-known, the height data in approximately 1900 need some discussion. The height data in 1900 is based on the NCD Risk Factor Collaboration (2016), which is probably the most authoritative source of cross-country historical height data. The data are mean heights for adults born in approximately 1900 and the data are based on sources that were representative of national, sub-national, or community population. Self-reported height is not used because it is subject to a systematic bias that varies by geography and socioeconomic characteristics, such as ethnicity and education. As documented in NCD Risk Factor Collaboration (2016), the quality standard of the height data is high.

The results of regressing (21)-(23) using height in 1900 as the regressor are presented in Table 5. The coefficients of height are highly significant and have the expected signs in the bivariate regressions (columns (1)-(3)) and in the regressions that include continental effects and latitude as controls (columns (4)-(6)). The principal results remain unaltered if countries with pre-1900 fertility transitions are excluded from the regressions (see online Appendix Table A6). As predicted by our model, absolute latitude is positively associated with economic development; however, the effect is not nearly as significant as in the bivariate regressions because height and continental effects are included in the regressions (the results without continental effects are not shown). Quantitatively, changes in height have approximately the same effects on the timing of the fertility transition and per capita income in 2000 as in the regressions using pre-1500 height, suggesting consistency across estimates and that height is influential for economic development regardless of whether height is measured in 1900 or in circa 1500.

For education, however, the economic significance of height is substantially higher in the estimates with height in 1900 than with pre-1500 height, suggesting that the estimates are sensitive to country selection. The sensitivity to sample selection may partly 


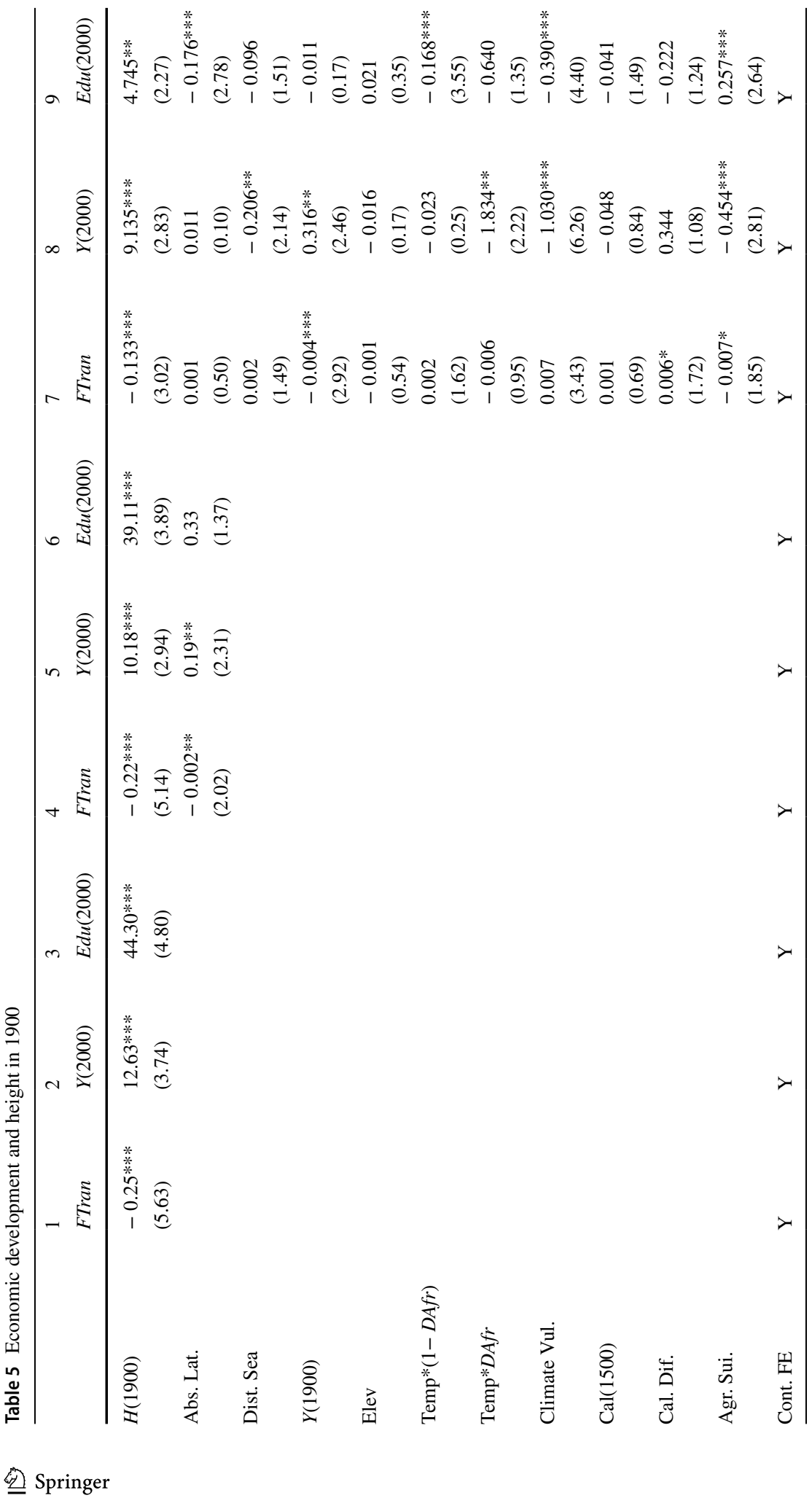




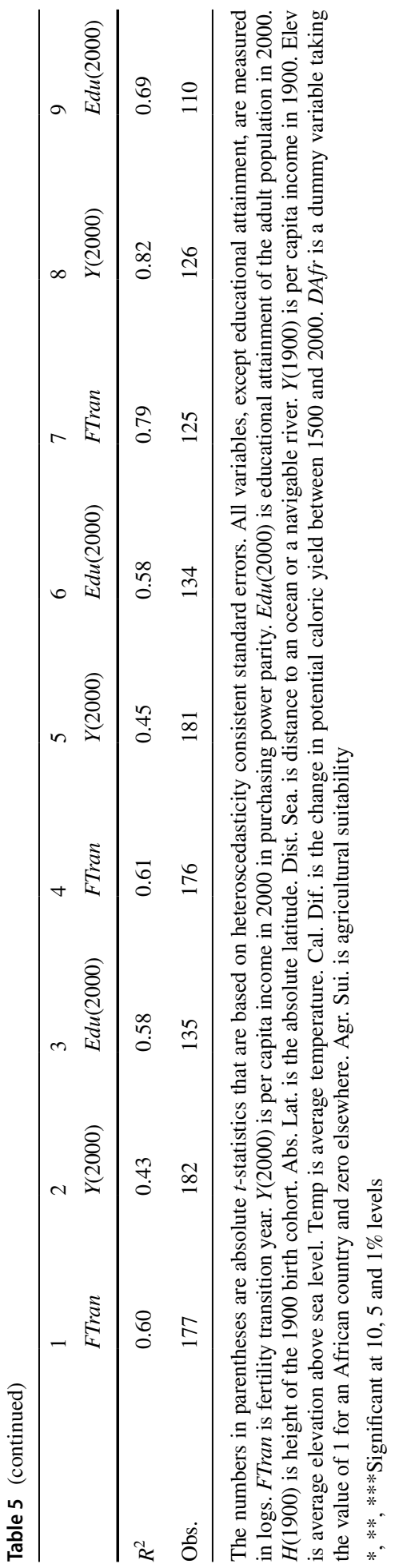


reflect that education is an imperfect measure of human capital and, therefore, does not adequately capture parents' investment in their offspring's education (see, e.g., Hanushek $\&$ Woessmann, 2011). Furthermore, per capita income in 1900, which is generally considered to be associated with investment in education, is insignificant in the regression in the last column in Table 5; thus, reinforcing the impression that education is not adequately capturing human capital. Finally, Caselli and Ciccone (2019) show that returns to education tend to be significantly higher in advanced than in developing countries because the skill premium is partly driven by technology, institutions and other factors.

As checks on the robustness of the results and endogeneity induced by the omission of variables that are simultaneously correlated with the outcome variables and height, we sequentially include control variables that are often considered essential for economic development (see, e.g., Galor \& Özak, 2016; Gallup et al., 1999; Hall \& Jones, 1999; Nunn \& Puga, 2012; Dell et al., 2012; Michalopoulos, 2012; Michalopoulos \& Papaioannou, 2018). As control variables, we include institutions (constraints on executive in 1900, social infrastructure in 1990, pre-industrial village democracy), geographic characteristics (precipitation, temperature, distance to an ocean or a navigable river, altitude, ruggedness, soil quality, agricultural suitability, post-1500 maximum potential caloric yield per hectare, parasitic and infectious disease in 1900), economic development (per capita income in 1900, the same year at which height is measured), and culture (individualism/collectivism). The results are presented and discussed in the online Appendix Section A1. In all cases, the coefficients of height remain statistically significant at the $1 \%$ level and with the expected signs in all the regressions, suggesting that the significance of height in the regressions is not caused by endogeneity induced by key omitted variables that are simultaneously correlated with height and the outcome variables. Overall, the results in this subsection give strong support for the hypothesis that height is a robust determinant of economic development.

To see how far we can push our hypothesis, we include the control variables that are statistically the most significant determinants of the outcome variables in the cross-country regressions (see online Appendix Section A1). Additionally, we include per capita income in 1900 as probably the variable that best controls for the level of economic development at the time at which the 1900 height cohort was born. The results are presented in the last three columns in Table 5. The coefficient of height is statistically significant in all three models; thus, giving strong supporting evidence that our baseline results are not driven by endogeneity due to omission of essential variables.

\subsubsection{Placebo tests}

Thus far, we have checked for endogeneity by including several variables that are potentially correlated with the error terms and used historical height data to ensure that there are no feedback effects from the outcome variables to height. As a final causality check, we undertake a placebo test by including the bilateral geographic distance to the UK for each individual country as an additional regressor in the cross-country baseline regressions in which the outcome variables consist of the fertility transition, and per capita income and education in 
2000. The geographical distance to the UK is a natural contender to latitude because the UK was the cradle of the First and Second Industrial Revolutions, which rapidly spread to neighboring countries through trade, migration, travel, and publications. The regression results are presented in Table A5 in the online Appendix with three sets of baseline regressors: pre1500 height, pre-1500 body mass, and height in 1900 . We additionally include continental fixed effects in the regressions with height in 1900. The coefficients of distance to the UK are all insignificant except in one case in which educational attainment is a significant positive function of distance-the opposite result of what we would expect. The coefficients of height remain significant at the $1 \%$ level and with the expected sign in all cases.

\subsection{Reduced form predictions: panel data evidence for Italy}

To give more substance to our theory, we use Italy as a case study to examine the influence of historical levels of height on contemporary regional inequalities. Italy makes a good case because it is an example of a country in which the gravity of economic activity, according to recent research, moved from the South towards the North in the later second half of the last millennium. Furthermore, using panel data over the period 1821-2001 for the Italian regions, we show that height is influential for education, the fertility transition and per capita income and, consequently, that height has been influential for the advantages that the North has enjoyed over the South over the past one and half centuries. ${ }^{11}$

\subsubsection{Reversal of fortune}

A well-known fact is that the northern part of Italy is today economically more developed than its southern counterpart. What is less well known, is that the South of Italy was probably more developed than the North in the sixteenth century. The leading paradigm has long been that an advanced northern Italian manufacturing sector has dominated a stagnant, backward southern agricultural sector that has prevailed at least since the medieval period (Epstein, 2003), since the South did not engage in foreign trade and lacked

\footnotetext{
11 A potential concern in the regressions for Italy is that the variations in latitude may be too narrow to give the sufficient identifying variation. Foster and Collard (2013), for example, find that humans conform to Bergmann's rule only when there are major differences in latitude and temperature between populations and for populations close and distant from the equator. To gain insight into the relationship between body mass and latitude gradient we undertake two sets of regressions (see online Appendix A2 for a detailed discussion and results).

In the first set, we regress height and body mass in 1500 against the absolute latitude at four different latitude quartiles, Q1-Q4, where Q4 is the highest latitude and Q1 the lowest. The overall significance of the coefficients of latitude are high $(p<0.001)$, which reinforces the finding that height and body mass are significantly positively related to latitude. Furthermore, we find that the null hypothesis that the latitude effects are highest at low (Q1) and high (Q4) latitudes can only be rejected in the body mass regression. This suggests that our proposed mechanism works reasonably well.

In the second set, we investigate whether the correlation between bilateral body weight distance and the absolute bilateral latitude distance between country $i$ and $j$ depends on the absolute bilateral latitude distance. To this end, the latitude distances between country $i$ and $j$ are interacted with decile dummies while controlling for longitude-effects in a regression with the absolute body mass distance as the dependent variable. Based on a Wald test for equality between the coefficients of deciles D1-D10, where D10 is the highest latitude decile, we are unable to reject the null hypothesis that the coefficients of D1-D10 are equal, suggesting that the size of the coefficient of bilateral body mass distance is independent of the latitude distance between country $i$ and $j$. There is, however, a tendency for large bilateral latitude distances to be statistically more significant than short distances, which is not surprising given that signal-noise ratio is likely to increase with distance.
} 
Fig. 4 Fertility in Italy 1600-2000

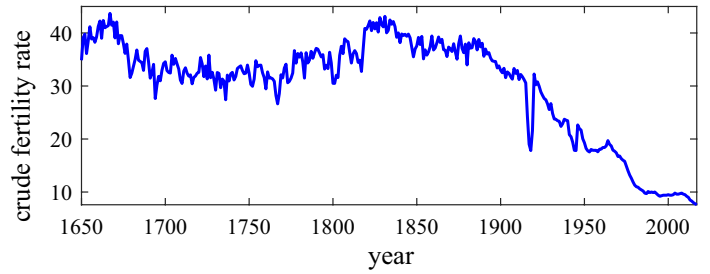

the entrepreneurial spirit of the North, it was dependent on the North for its manufacturing products in exchange for staple agricultural products (see, e.g. Luzzatto, 1948, pp. 103-115).

However, new studies have rejected the old paradigm. Malanima (1998), for example, finds that the biggest Italian cities were located for the most part in the South of the Italian peninsular and in Sicily during the period 1000-1300, while only some maritime cities and very few in the interior had attained a prominent position in the center and in the North of Italy. Based on detailed analysis of archival documents and data, Epstein (2003) shows that the South of Italy was highly developed during the medieval period and showed resilience to economic shocks. In response to the fourteenth-century crisis, Sicily restructured its regional markets, resulting in a significant expansion of income and population size (Epstein, 2003). In the second half of the fifteenth century, for example, Sicily experienced a two-fold increase in its population size (the increase was $20 \%$ for Italy over the same period, Madsen et al. 2019). Even if some of the population expansion was driven by a comparatively strong convergence towards the steady state following the Black Death, the population expansion could not have taken place without marked technological or efficiency advances. Moreover, at no time during the fifteenth and sixteenth centuries did less than $30 \%$ of the population in Southern Italy live in the urban centers (Malanima, 1998), suggesting that the South of Italy was already quite developed in this period, but eventually fell behind the North.

\subsubsection{Econometric evidence for the Italian regions}

To show that height has been a factor in the reversal of fortune between the North and South of Italy, we use decennial data for the existing 19 Italian regions, spanning the maximum period 1821-2001, again, using fertility, education and income as outcome variables. Most of the data are reconstructions from historical sources and before 1918, the height data are derived from the height of military recruits, as detailed in the online Appendix Section A4. ${ }^{12}$ Furthermore, we check whether height during the Roman Empire period predicts contemporaneous outcome variables. To get a long perspective on the timing of the fertility transition in Italy, Fig. 4 displays the crude fertility rate (births per 1000 population) for Italy over the period 1650-2016. The fertility rate fluctuated around a relatively constant level over the period 1650-1890 and since then transited to the current level over the approximate period 1890-1980. In the estimates we focus on the period 1891-1981, or periods in-between, while allowing for long lags in height.

\footnotetext{
12 Although there are 20 administrative regions in Italy today there are only 19 regions listed in the historical source material we have used, usually because the Abruzzi and Moulise regions are merged.
} 


\subsubsection{Fertility as the outcome variable}

The regression results with the level or the change in fertility as the outcome variable are presented in Table 6 . The crude fertility rate, $C F R$, is the outcome variable and height is lagged 6 or 13 periods (60 or 130 years) to cater for potential endogeneity. The length of the lags is dictated by the first year at which the data are available. We use the level as well as the change in fertility as outcome variables, which is a consideration that is not too important since fertility rates were not that different before the fertility transition, but the fertility discrepancy increased during the course of the fertility transition: The cross-region standard deviation of the log of the $C F R$ was 0.073 in 1871 , shortly before the fertility transition, and increased gradually to 0.276 in 1931 .

In the bivariate regressions covering the period 1891-1981 in the first two columns in Table 6, the coefficients of height are highly significantly negative and have approximately the same magnitude regardless of whether time-dummies are included in the estimates. In column (3), latitude and a three-period lag of population density are added to the model, noting that population density is used for income because per capita income data are not available before 1891. Population density is lagged only three periods because it is first available from 1861. The coefficients of latitude and population density are significantly negative and, being highly significant, height still has a significant independent effect on fertility even when economic development and latitude are accounted for. Measuring the dependent variable in six-period differences (column (4)), the coefficients of all the regressors are again significantly negative and the magnitudes of the coefficients are not that dissimilar to those in the level regression in column (3). This result underscores that fertility rates across regions were not that different before the fertility transition and, therefore, reconfirms that level regressions are as informative as first-difference regressions.

Thus far, we have tested our model in a panel setting. Cross section regressions are presented in the last four columns in Table 6. Consider first the estimates in columns (5)-(7), in which fertility in 1981 is regressed on height in 1850 . Here, the year 1850 represents a year at which the fertility transition had not started and the broad population in all regions lived close to subsistence level, noting that per capita income in Italy was flat over the period 1700-1870 before it started to increase. Furthermore, the cross-state variation in income was probably very low in 1850 since the $16 \%$ standard deviation of per capita income across regions in 1891 increased to $33 \%$ in 1936. The coefficients of height are all significant, even when per capita income in 1891 and latitude are controlled for. An important aspect of these estimates is that the coefficient of height is unaffected by the inclusion of per capita income in 1891 (column (7)), suggesting that the level of income in 1890 does not influence the differentiated timing of the fertility transition across Italian regions.

Finally, fertility in 1931 is regressed on height during the Roman Empire for the 12 regions for which data are available, where the cross-region variation in the timing of the fertility transition is best captured in 1931 (using fertility in 1911, 1931 and 1936 give the same principal results). Fertility measured close to 1981, for example, is too late because the fertility transition was completed in all regions at this time and the years around 1891 are too early because the fertility transition had not started in any of the regions at that time. The coefficient of height is significantly negative at the $10 \%$ level (column (8)), but becomes insignificant when latitude is included in the model (the results are not shown). However, the insignificance of height when latitude is controlled for does not undermine height as a principal driver of fertility because measurement error for height during the Roman Empire period is likely to be large and correlated with latitude. 


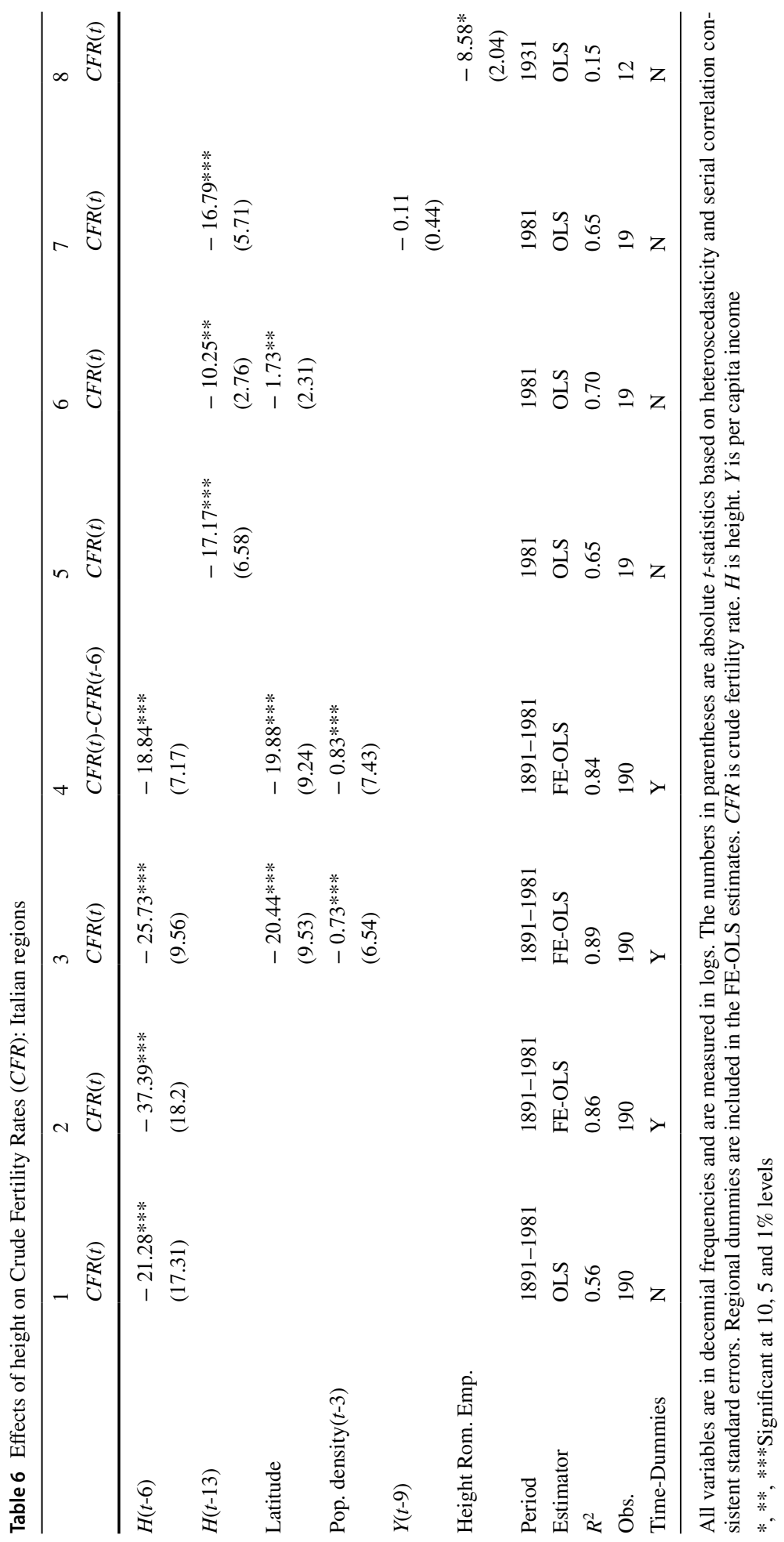




\subsubsection{Education as the outcome variable}

According to the QQ-tradeoff in our theoretical framework, the fertility decline is associated with a simultaneous increase in education as parents can devote more resources per child to education since they lower their fertility. To check for the influence of height on education during the fertility transition, we treat, as outcome variables, the levels and changes in literacy and gross enrollment rates (GER), measured as the fraction of the population of school age that is enrolled in primary, secondary and tertiary education. The estimates are presented in Table 7. The coefficient of the six-period lag of height is a highly significant determinant of gross enrollment rates regardless of whether latitude and lagged population density are included in the regression (columns (1)-(3)). The coefficient of height remains significantly positive when a six-period change in gross enrollment rates is the outcome variable and latitude and population density are included as control variables (column (4)), noting that the data period starts in 1931 because gross enrollment rates are first available from 1871.

Six-period changes in literacy rates are regressed against a six-period lag in height, latitude, and a three-period lag in population density in columns (5) and (6) in Table 7. Note that 1911 and 1931 are the end years for the literacy estimates because compulsory schooling years increased during the twentieth century and, therefore, ensured that literacy rates converged across regions such that the entire population was literate at the end of the century. The coefficients of literacy are highly significant and comparable to the coefficient of gross enrollment rates in column (4). To get a long-term perspective on the effects of height on literacy, we regress the level of literacy in 1931 on a 10-period lag in height and a four-period lag in per capita income (column (7)). The coefficient of height remains significantly positive at the $1 \%$ level. Finally, we regress gross enrollment rates and literacy rates on height during the Roman Empire. The coefficients of height are significant at the 1-percent level; thus giving further support to the hypothesis that height was influential for the rise in education.

\subsubsection{Effects of height on per capita income}

As a final test of the reduced form effects of height on economic development, we regress the level and the change in per capita income on latitude and lags of height and income (Table 8). The coefficients of the six-period and even the 13-period lags in height are highly significant in the regressions in the first five columns, regardless of whether timedummies, lagged income and latitude are included in the regressions and whether the level or the growth in income is the outcome variable. Furthermore, the coefficient of height in the Roman Empire period is significantly positive.

Based on the coefficients of height in the regressions in the third column in Tables 6 , 7 and 8 , a one standard deviation increase in height in 1891 (1.3\%) is associated with a $33.4 \%$ decrease in the crude fertility rate, a $9.5 \%$ increase in the gross enrollment rate, and a $57.3 \%$ increase in per capita income. This results suggest that the cross-state variation in height was influential for the differential development in the Italian states. 


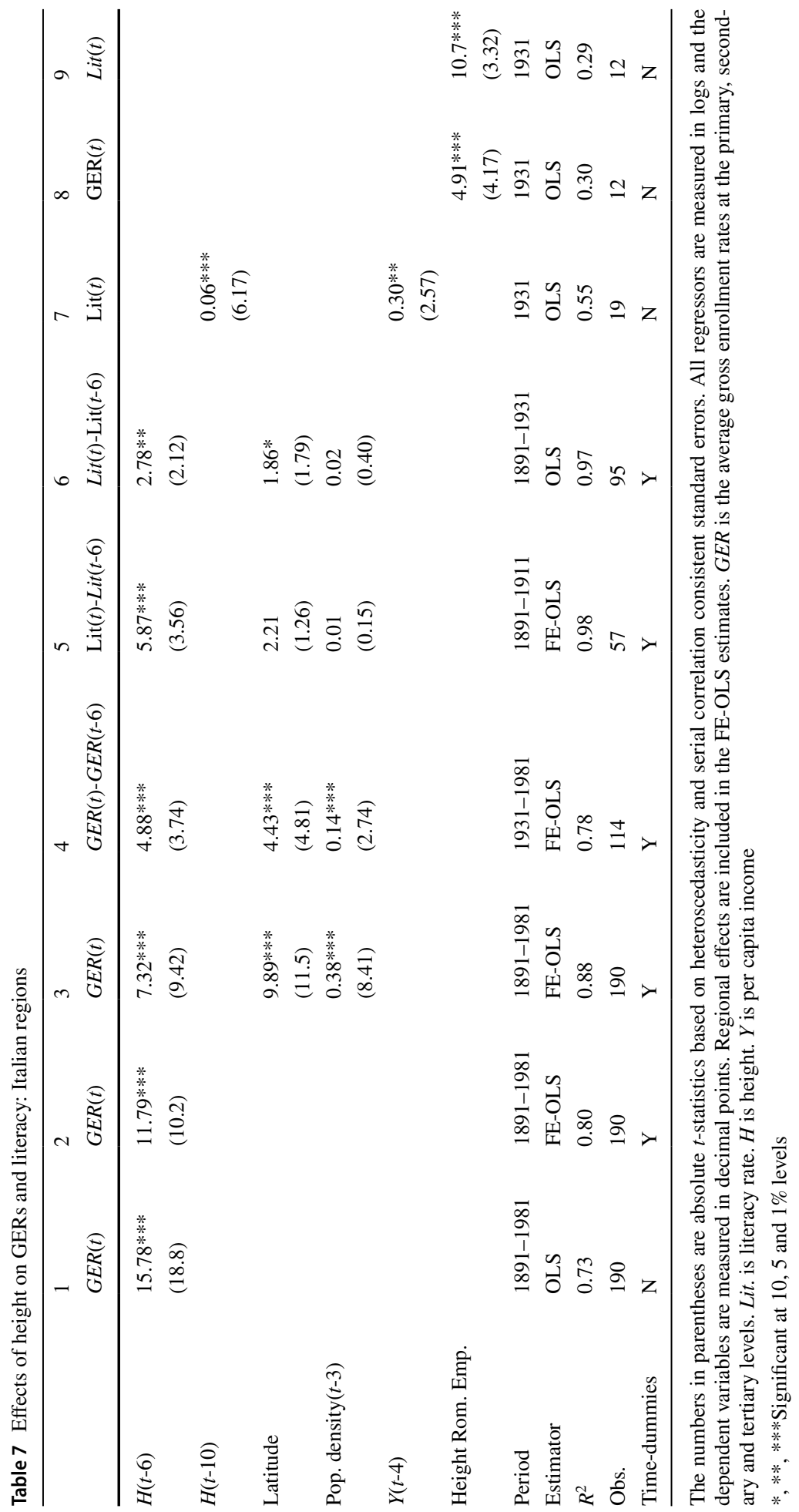


Table 8 Effects of height on per capita income: Italian regions

\begin{tabular}{|c|c|c|c|c|c|c|c|}
\hline & 1 & 2 & 3 & 4 & 5 & 6 & 7 \\
\hline & $Y(t)$ & $Y(t)$ & $Y(t)$ & $Y(t)$ & $Y(t)-Y(t-3)$ & $Y(t)$ & $Y(t)$ \\
\hline \multirow{2}{*}{$H(t-6)$} & $27.81 * * *$ & $54.43 * * *$ & $44.07 * * *$ & & $21.07 * * *$ & & \\
\hline & (13.61) & (19.04) & $(19.55)$ & & $(5.28)$ & & \\
\hline \multirow[t]{2}{*}{$H(t-13)$} & & & & $15.79 * * *$ & & $5.97 * *$ & \\
\hline & & & & $(6.70)$ & & $(2.46)$ & \\
\hline \multirow[t]{2}{*}{ Latitude } & & & $32.64 * * *$ & & $34.33 * * *$ & $2.10 * * *$ & \\
\hline & & & (12.06) & & $(5.72)$ & $(4.56)$ & \\
\hline \multirow[t]{2}{*}{$Y(t-9)$} & & & & & & $0.35 * * *$ & \\
\hline & & & & & & $(2.95)$ & \\
\hline \multirow[t]{2}{*}{ Pop. density $(t-3)$} & & & $1.02 * * *$ & & $1.37 * * *$ & & \\
\hline & & & $(8.62)$ & & (7.15) & & \\
\hline \multirow[t]{2}{*}{ Height Rom. Empire } & & & & & & & $9.21 *$ \\
\hline & & & & & & & (1.86) \\
\hline Period & $1891-1981$ & 1891-1981 & $1891-1981$ & 1981 & $1921-1981$ & 1981 & 1931 \\
\hline Estimator & OLS & FE-OLS & FE-OLS & OLS & FE-OLS & OLS & OLS \\
\hline$R^{2}$ & 0.44 & 0.86 & 0.93 & 0.75 & 0.86 & 0.88 & 0.11 \\
\hline Obs. & 190 & 190 & 190 & 19 & 133 & 19 & 12 \\
\hline Time-dummies & $\mathrm{N}$ & $\mathrm{Y}$ & $\mathrm{Y}$ & $\mathrm{N}$ & $\mathrm{Y}$ & $\mathrm{N}$ & $\mathrm{N}$ \\
\hline
\end{tabular}

The numbers in parentheses are absolute $t$-statistics based on heteroscedasticity and serial correlation consistent standard errors. Regional dummies are included in the FE-OLS estimates. $Y=$ per capita income. $H$ is height. All variables are in decennial frequencies and are measured in logs

$*$, **, ***Significant at 10,5 and $1 \%$ levels

\subsection{Testing the take-off prediction}

The key mechanism established by unified growth theory (UGT) as the driver of the fertility transition and the take-off to modern growth is technological progress in conjunction with a child quantity-quality trade-off. Technological progress increases the return to education such that parents start investing in education and reduce their fertility (see Galor \& Weil, 2000; Galor, 2011; see Madsen \& Strulik, 2020 for recent empirical support of the UGT mechanism). In this section we examine whether the UGT mechanism is mediated by height, as proposed by our theory. Specifically, to test whether international technological progress acted as a mechanism that facilitated an early fertility transition in the countries with the tallest populations through the channel of imports, we infer whether height acts as a mediator through its interaction with transmission of technology. For this purpose, we estimate the following model for a panel of 18 OECD countries over the period 1840-1980:

$$
\log \text { FerG }_{i t}=\lambda_{0}+\lambda_{1} \log H_{i t}+\lambda_{2} \log (\text { Pat } / \text { Pop })_{i t}^{F}+\lambda_{3} \log H_{i t} \log (\text { Pat } / \text { Pop })_{i t}^{F}+C D+T D+\epsilon_{4, i t},
$$


Table 9 Effects of international technology on fertility through height

\begin{tabular}{|c|c|c|c|c|c|}
\hline & $H(t)$ & $\left((\text { Pat/Pop })^{F}\right)(t)$ & $H(t)^{*}\left((P a t / P o p)^{F}\right)(t)$ & Obs. & Sobel \\
\hline FerG & $-1.59(2.90) * * *$ & $3.20(13.22)^{* * *}$ & $-0.63(13.22)^{* * *}$ & 2538 & \\
\hline $\begin{array}{l}\text { Height as } \\
\text { mediator }\end{array}$ & & & & & $68.8 * * *$ \\
\hline
\end{tabular}

All variables are measured in logs including each variable in the interaction term. FerG is the general fertility rate. $H$ is height. $(\text { Pat/Pop })^{F}$ is patent-population ratio. Annual data over the period 1840-1980 are used. The country sample comprises Austria, Belgium, Canada, Denmark, Finland, France, Germany, Greece, Ireland, Italy, the Netherlands, Norway, Portugal, Spain, Sweden, Switzerland, the UK and the US. Country and time-dummies are included in the regressions and the $t$-ratios (in parentheses) are based on serial correlation and heteroscedasticity consistent standard errors. Sobel $=$ Sobel $t$-test for height as a mediator of the international technology transmission under the null hypothesis that height has not acted as a mediator

$*$, **, ***Significant at 10,5 and $1 \%$ levels

where $\mathrm{FerG}$ is the general fertility rate (number of births by females in the reproductive age, 15-44); $H$ is height; $(\text { Pat/Pop })^{F}$ is import-weighted foreign patent intensity (foreign patents divided by their population size); $C D$ is country dummies; and $T D$ is time dummies. The estimation period is sufficiently long to cover the entire fertility transition of the countries included in our sample. The country sample is listed in the notes to Table 9 and the data sources are described in the online Appendix.

Foreign patent intensity is estimated as the weighted number of patent applications of residents divided by the population using data for 21 OECD countries (including the 18 countries used here and listed inn the notes to Table 9). Bilateral imports as the share of GDP of the exporting country are used as weights under the assumption that imports of intermediate products give the importing country an opportunity to produce more efficiently. For details on the weighting schedule, which is not based on simple bilateral weights but on income of the exporting country, see Madsen (2007). The country sample is dictated by data availability. Almost all the data are available over the estimation period and are of high quality. The height data are for males and are representative of the male population since they are derived from military draft recruitment files; recruitment was compulsory for most countries during the considered period.

International technology spillovers influence fertility rates directly and indirectly through height. For $\lambda_{3}<0$, international technological progress has a potentially stronger effect on fertility the taller individuals are, on average, in the home country. Conversely, if $\lambda_{3}=0$, then height is not a mediator of foreign technological progress.

The results of regressing $\mathrm{FerG}$ on height, foreign technology, and their interaction are presented in Table 9. The coefficient of the interaction term is highly significantly negative, implying that transmission of foreign patent intensity through the channel of imports amplifies the negative fertility effect of height. In other words, for a given height, an increase in the foreign patent intensity reduces the fertility rate because it pays to invest more in education at the expense of fertility. Furthermore, for a given level of foreign patent-intensity, an increase in the height of the population shows that a lower level of technology is needed to elicit a fertility response when the population is relatively tall.

The effects of the increase in foreign patent intensity on fertility through height can be estimated from the derivative of (24): 


$$
\begin{aligned}
\mathrm{d} \log \text { FerG } & =\left(\lambda_{2}+\lambda_{3} \log H\right) \mathrm{d} \log \left(\frac{\text { Pat }}{\text { Pop }}\right) \\
& =(3.2-0.63 \log H)\left[\log \left(\frac{\text { Pat }}{\text { Pop }}\right)_{1840}-\log \left(\frac{\text { Pat }}{\text { Pop }}\right)_{1980}\right]=-0.31,
\end{aligned}
$$

where the derivative of patent-intensity is estimated as the average change in the importweighted foreign patent-intensity for the 18 OECD countries in our sample over the period $1840-1980$ and height is measured as the average height in 1980. This exercise shows that the expansion of the world technology frontier over the period 1840-1980 resulted in a $31 \%$ decline in the general fertility rate mediated by height over the same period. Since the average fertility rates declined by $54 \%$ over the same period, our model goes a long way in explaining the fertility transition in the OECD countries.

Finally, to formally test our hypothesis that external triggers affect fertility through height (mediator) we conduct a Sobel test, which essentially tests whether there is a significant reduction in the effect coming from the (Pat/Pop)-term in the fertility regression when height is added to the model and, consequently, whether the mediator effect is statistically significant. The null hypothesis that height is not the mediator is strongly rejected by the Sobel test $(t=69)$, see Table 9. In sum, the evidence presented gives support to the hypothesis that transmission of technological progress effectively triggered the fertility transition in the OECD and that this process was mediated by height.

\subsection{Height and other approximate determinants of economic development ${ }^{13}$}

As a final exercise, we test the extent to which body size measured by height in 1900 contributed to per capita income in 2000 when institutions, culture, geographic characteristics, health insults and latitude are accounted for. First, however, we regress income on latitude and each approximate determinant of income. We start up from the fundamental fact that absolute latitude is positively correlated with per capita income and latitude is a proxy for more fundamental growth determinants. The results are presented in Table 10 including the partial correlation coefficients (in brackets underneath the coefficients) to gain insight into the degree of association between income and latitude when the effects of the control variables are removed.

Starting from column (1), the coefficient of latitude is significantly positive and has a partial correlation coefficient, $r^{2}$, of 0.23 . The $t$-value and the $r^{2}$ of latitude are reduced substantially when continental fixed effects are included in the regression: Without continental fixed effects, the $t$-value is 6.6 and the $r^{2}$ is 0.44 (not shown in the table). In column (2) we add height in 1900 to the regression in column (1). Height as well as latitude are contributing about half each to the explanation of the variance in per capita income. When the distance to the ocean or a navigable river and climate vulnerability are added to the estimate in column (1), latitude becomes insignificant, suggesting that latitude, to a large extent, captures geographical effects. We include climate vulnerability and distance to the ocean and a navigable river in the regression in column (3). The impact of climate vulnerability may have been an outcome of a long evolutionary process. High climate vulnerability, for example, could have delayed the Neolithic revolution because domestication of agriculture would not have been a viable alternative to hunter-gather living. The coefficients of climate

$\overline{13}$ We are grateful to one of the anonymous referees for suggesting the tests in this section 


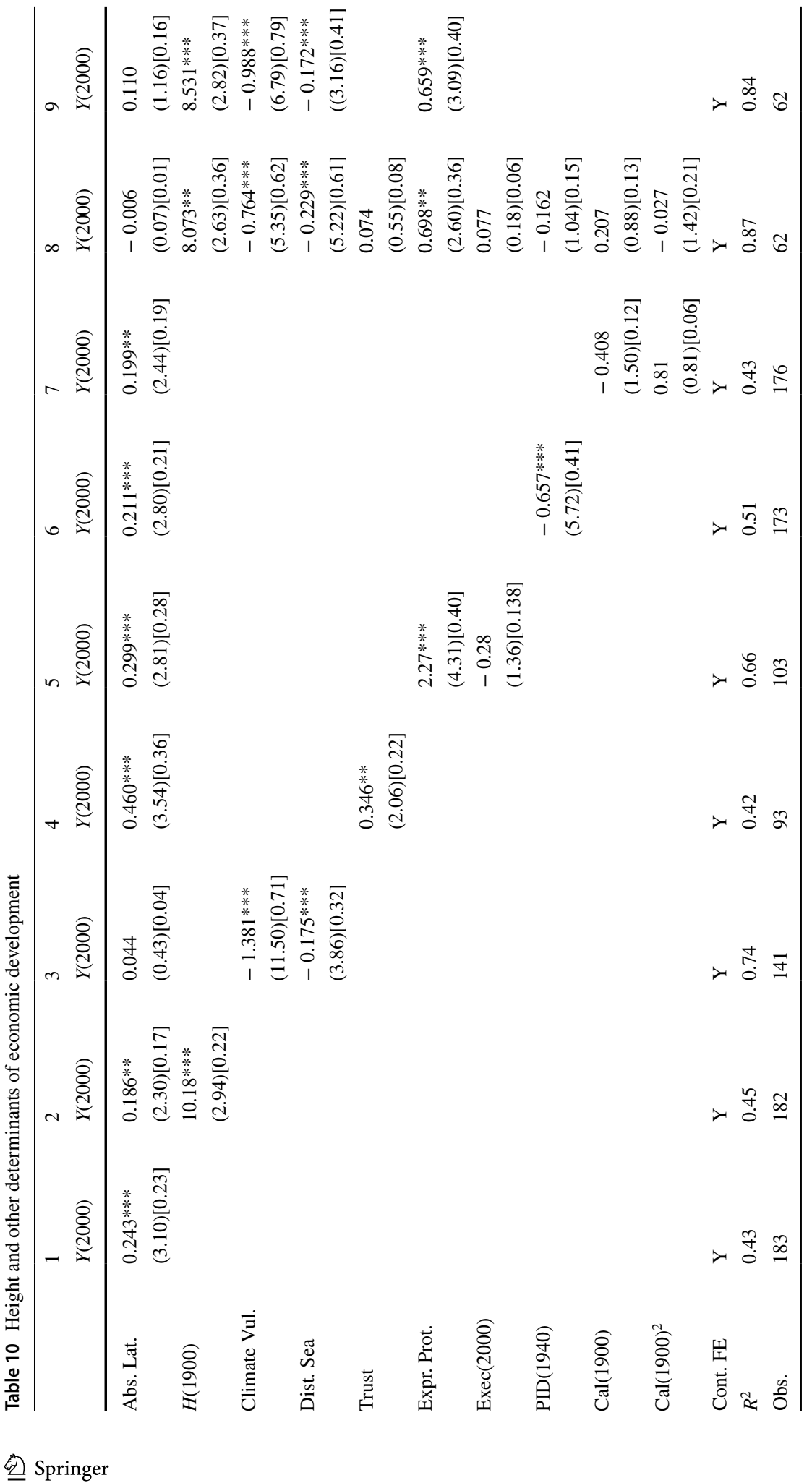




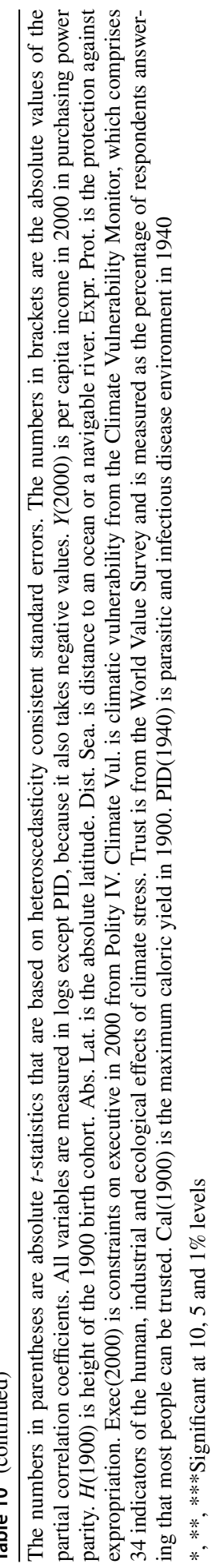


vulnerability and distance to ocean, as expected, have negative signs, while the coefficient of latitude is insignificant, again suggesting that the continental dummies tend to capture the geographic determinants of income.

Next, consider trust as an indicator of culture. Trust creates wealth by reducing transaction costs and corruption. Since trust is just one of several dimensions of culture, limited data availability and the difficulties with the measurement of culture renders it difficult to test how much culture has contributed to economic development. As a key cultural trait, Gorodnichenko and Roland (2017) find that an individualist culture generates more innovations than a collectivist culture because of social status rewards associated with innovation in an individualistic culture. However, we rely on trust as an indicator of culture because the data are available for approximately twice the number of countries as the individualist-collectivist dimension provided by the World Value Survey. The coefficient of trust is significantly positive in the regression in column (4). Turning to institutions we follow Acemoglu et al. (2002) by using protection against expropriation and constraints on the executive as institutional indicators (column (5)). The coefficient of expropriation protection is significantly positive, while constraints on the executive is insignificant. Note, however, that since the indicators of institutions are present day experiences, they may not reflect institutional roots or root causes of institutions but, instead, may be an outcome of economic development and cultural roots. As displayed in column (6), the coefficient of parasitic and infectious disease in 1940, PID(1940), is significantly negative, suggesting that productivity is adversely affected by a high-disease environment. PID adversely affects productivity by slowing cognitive development in childhood and reducing the ability to work at full potential etc. (Murray \& Schaller, 2010). In column (7) we include caloric yield in 1900, Cal(1900), in levels and squared; however, both are insignificant.

In the estimates in column (8) we include all variables. The significance and signs of the coefficients are largely consistent with the results in columns (2)-(6). An exception is PID(1940), which is rendered insignificant by the inclusion of all the confounding factors and not the reduced sample size (PID(1940) remains highly significantly negative when the confounding variables are excluded from the model). Excluding the insignificant variables by applying the general-to-specific model reduction procedure, except for latitude, yields the estimates in column (9). Distance to an ocean or a navigable river, protection against expropriation, and height in 1900 have absolute correlation coefficients of approximately the same sizes, while that of climate vulnerability takes the highest absolute value. It is noticeable how robust the coefficient of height is to inclusion of confounding factors as signified by the values of $t$ and the partial coefficients, $r^{2}$. The insensitivity of the coefficient of height to inclusion of confounding factors suggests that height affects income through channels other than culture, institutions and geographic factors.

\section{Conclusion}

In this paper we have proposed a theory of the reversal of fortune; the remarkable shift in the latitude gradient with respect to economic development, which appears to have occurred over the last roughly 500 years. We advance the hypothesis that differences in physiological constraints faced by individuals in different geographical locations can account for the observed reversal. In places where humans were bigger historically, the physiological costs of children were greater, leading to low population density early on. However, the relatively high cost of children simultaneously provided a comparative 
advantage in child quality investments for physiologically bigger parents, which worked to bring forth an earlier take-off. Hence, in the contemporary era, historical body size should be positively correlated with economic development. Since average body mass and height exhibit a clear latitude gradient (Bergmann's rule), our theory suggests that this physiological mechanism could have been responsible, in part, for the changing latitude gradient in the course of history: A negative link between absolute latitude and population density in 1500 C.E. but a positive correlation between absolute latitude and economic development today.

In order to corroborate this hypothesis, we have developed a unified growth model which captures the above elements. Importantly, the model allows us to examine the robustness of the highlighted explanation to an important countervailing mechanism. In historical times it is plausible that a higher density of people led to more ideas. This scale effect could work to circumvent the physiological mechanism, thereby allowing the more innovative society inhabited by more but physiologically smaller people to take off earlier. We find, however, that even if knowledge diffusion is gradual, and possibly incomplete, the physiological mechanism is likely to prevail.

To substantiate the empirical implications of the theory we examine the following chain of events. We show that population density, as a proxy for economic development, was negatively related to body mass and height in the pre-1500 period. However, as the world technology frontier increased at a sufficiently strong pace, the returns to education increased and taller populations had more to gain from reducing their fertility and investing in their offspring's education instead. Using annual data for 18 OECD countries over the period $1840-1980$, we find that the fertility decline in response to the international transmission of technology through the channel of imports was significantly mediated through height. From the parameter estimates we inferred that more than half of the fertility transition in these OECD countries over the period 1880-1980 can be explained by the interaction between height and international technology transmission.

Based on cross-country estimates for countries in the world, we show that countries with the tallest populations and highest body mass in circa 1500 experienced the earliest fertility transitions and have the highest contemporary level of education and per capita income. Using height as a proxy for body mass in 1900, we arrive at the same results: The year of the fertility transition and per capita income and education are significantly related to height in 1900, noting that we find height to be an excellent proxy for body mass. Furthermore, we find that the height of the 1900 birth cohort remains a significant determinant of economic development when the effects of the following factors are allowed for: Per capita income in 1900, different aspects of institutions and culture, and several geographic variables, such as weather, distance to navigable water, climatic vulnerability, ruggedness among several other controls. Finally, using data for Italian regions over the period 1821-2001, we showed that fertility, education, and income are significantly associated with height 6-13 decades earlier as well as with height in Roman times. Overall, our results show that weight and height have been significant determinants of economic development after circa 1500 and the results are robust to often-used indicators of economic development. We would like to stress, however, that our results should be interpreted from the perspective that body size was a contributor but not the sole cause of the timing of the fertility transition.

The findings of the paper have implications for our understanding of the world inequality path over the past five centuries. While the reversal of fortune hypothesis of Acemoglu et al. (2002) has been the leading explanation for the development path across the world, we have shown that geographical factors and not only institutions have 
shaped this development. In fact, we find that the reversal is not limited to the West exploiting its former colonies since it also occurred within Europe.

\section{Mathematical Appendix}

When the education constraint is not binding $\left(e_{t}>0\right)$, while the subsistence constraint is binding $\left(x_{t}=0\right)$, we obtain the following solution from the optimality conditions (9):

$$
\begin{aligned}
n_{t} & =\frac{(1-2 \gamma) v A_{t}\left(y_{t}-B_{t}\right)}{v A_{t} \rho B_{t}-\bar{h}} \\
c_{t} & =\frac{\gamma\left(v A_{t} \rho B_{t}-\bar{h}\right)}{v A_{t}(1-2 \gamma)} \\
e_{t} & =\frac{\gamma \rho v A_{t} B_{t}-(1-\gamma) \bar{h}}{(1-2 \gamma) v A_{t}} .
\end{aligned}
$$

At this "Subsistence-cum-Education" steady state, fertility depends positively on income, while the solution for $c_{t}$ and $e_{t}$ coincide with the interior solutions (10b) and (10c). Consequently, the education threshold remains at $\bar{A}$ and is crossed earlier in countries populated by bigger people. This implies, qualitatively, a reversal of fortune as for the "ordinary" sequence of regimes discussed in the main text. Notice that the education threshold does not depend on income or population size and that technology $A$ cannot decline. Once education started, Malthusian dynamics cannot drive the economy back to subsistence. Instead, the economy eventually crosses the subsistence threshold and reaches the modern regime.

Supplementary Information The online version contains supplementary material available at https://doi. org/10.1007/s10887-021-09193-y.

Acknowledgements We would like to thank Thilo Albers, Francois Bourguignon, David de la Croix, Oded Galor, Nippe Lagerlöf, Anastasia Litina, Omar Licandro, Fabio Mariani, David Weil, Asger Wingender and participants at CESifo summer institute (Demographic Change and Long-Run Development), the 8th Louvain Symposium on Economic Dynamics, the workshop on "The Long Shadow of History: The Role of Geographical, Institutional, Cultural, and Human Factors in Comparative Economic Development" at the University of Tel Aviv, the conference "Deep Roots of Economic Growth" in Naples, and seminars at the University of Pretoria, the University of Leicester, and Humboldt University, Berlin, as well as three anonymous reviewers for helpful comments. Jakob B. Madsen gratefully acknowledges financial support from the Australian Research Council (Grants DP150100061 and DP170100339).

Funding Open Access funding enabled and organized by Projekt DEAL.

Open Access This article is licensed under a Creative Commons Attribution 4.0 International License, which permits use, sharing, adaptation, distribution and reproduction in any medium or format, as long as you give appropriate credit to the original author(s) and the source, provide a link to the Creative Commons licence, and indicate if changes were made. The images or other third party material in this article are included in the article's Creative Commons licence, unless indicated otherwise in a credit line to the material. If material is not included in the article's Creative Commons licence and your intended use is not permitted by statutory regulation or exceeds the permitted use, you will need to obtain permission directly from the copyright holder. To view a copy of this licence, visit http://creativecommons.org/licenses/by/4.0/. 


\section{References}

Acemoglu, D., Johnson, S., \& Robinson, J. A. (2002). Reversal of fortune: Geography and institutions in the making of the modern world income distribution. Quarterly Journal of Economics, 117, 1231-1294.

Aiyar, S., Dalgaard, C.-J., \& Moav, O. (2008). Technological progress and regress in pre-industrial times. Journal of Economic Growth, 13, 125-144.

Allen, J. A. (1877). The influence of physical conditions in the genesis of species. Radical Review, 1, $108-140$.

Ashraf, Q., \& Galor, O. (2011). Dynamics and stagnation in the Malthusian epoch. American Economic Review, 101, 2003-2041.

Ashraf, Q. H., Galor, O., \& Klemp, M. (2020). The ancient origins of the wealth of nations. Bravo Working Paper No. 2020-22.

Astrand, P. O., \& Rodahl, K. (1970). Body dimensions and muscular work. In P. O. Astrand \& K. Rodahl (Eds.), Textbook of work physiology (pp. 321-39). McGraw-Hill.

Becker, G. (1960). An economic analysis of fertility. In Demographic and economic change in developed countries. Conference of the Universities-National Bureau Committee for Economic Research, a Report of the National Bureau of Economic Research (pp. 209-240). Princeton University Press.

Bergmann, C. (1847). Ueber die Verhältnisse der Wärmeökonomie der Thiere zu Ihrer Grösse. Gottinger Studien, 3, 595-708.

Caselli, F., \& Ciccone, A. (2019). The human capital stock: A generalized approach: Comment. American Economic Review, 109(3), 1155-74.

Cervellati, M., \& Sunde, U. (2005). Human capital formation, life expectancy, and the process of development. American Economic Review, 95, 1653-1672.

Charnov, E. L. (1991). Evolution of life history variation among female mammals. Proceedings of the National Academy of Sciences of the United States of America, 88, 1134-1137.

Charnov, E. L. (1993). Life history invariants. Oxford University Press.

Charnov, E. L., \& Ernest, S. K. M. (2006). The offspring-size/clutch-size trade-off in mammals. The American Naturalist, 167, 578-82.

Cowgill, L. W., Eleazer, C. D., Auerbach, B. M., Temple, D. H., \& Okazaki, K. (2012). Developmental variation in ecogeographic body proportions. American Journal of Physical Anthropology, 148(4), 557-570.

Dalgaard, C.-J., Hansen, C. W., \& Strulik, H. (2021). Fetal origins-A life cycle model of health and aging from conception to death. Health Economics, 30(6), 1276-1290.

Dalgaard, C.-J., Knudsen, A. S., \& Selaya, P. (2020). The bounty of the sea and long-run development. Journal of Economic Growth, 25(3), 259-295.

Dalgaard, C. J., \& Strulik, H. (2014). Optimal aging and death: Understanding the Preston curve. Journal of the European Economic Association, 12(3), 672-701.

Dalgaard, C.-J., \& Strulik, H. (2015). The physiological foundation of the wealth of nations. Journal of Economic Growth, 20, 37-73.

Dalgaard, C.-J., \& Strulik, H. (2016). Physiology and development: Why the West is taller than the rest. Economic Journal, 126, 2292-2323.

De la Croix, D., \& Licandro, O. (2013). The child is father of the man: Implications for the demographic transition. Economic Journal, 123, 236-261.

Dell, M., Jones, B. F., \& Olken, B. A. (2012). Temperature shocks and economic growth: Evidence from the last half century. American Economic Journal: Macroeconomics, 4(3), 66-95.

Epstein, S. R. (2003). An island for itself: Economic development and social change in late medieval Sicily. Cambridge University Press.

Foster, F., \& Collard, M. (2013). A reassessment of Bergmann's rule in modern humans. PloS One, 8(8), e72269.

Gallup, J. L., Sachs, J. D., \& Mellinger, A. D. (1999). Geography and economic development. International Regional Science Review, 22(2), 179-232.

Galor, O. (2011). Unified growth theory. Princeton University Press.

Galor, O. (2012). The demographic transition: Causes and consequences. Cliometrica, 6(1), 1-28.

Galor, O., \& Moav, O. (2002). Natural selection and the origin of economic growth. Quarterly Journal of Economics, 117, 1133-1191.

Galor, O., \& Özak, Ö. (2016). The agricultural origins of time preference. American Economic Review, 106(10), 3064-3103.

Galor, O., \& Savitskiy, V. (2018). Climatic roots of loss aversion. National Bureau of Economic Research Working Paper No. w25273. 
Galor, O., \& Weil, D. (2000). Population, technology and growth: From Malthusian stagnation to the demographic transition and beyond. American Economic Review, 90, 806-828.

Gorodnichenko, Y., \& Roland, G. (2017). Culture, institutions, and the wealth of nations. Review of Economics and Statistics, 99(3), 402-416.

Gustafsson, A., \& Lindenfors, P. (2009). Latitudinal patterns in human stature and sexual stature dimorphism. Annals of Human Biology, 36, 74-87.

Hagen, E. H., Barrett, H. C., \& Price, M. E. (2006). Do human parents face a quality-quantity tradeoff? Evidence from a Shuar community. American Journal of Physical Anthropology, 130, 405-418.

Hall, R. E., \& Jones, C. I. (1999). Why do some countries produce so much more output per worker than others? The Quarterly Journal of Economics, 114(1), 83-116.

Hancock, A. M., Clark, V. J., Qian, Y., \& Di Rienzo, A. (2010). Population genetic analysis of the uncoupling proteins supports a role for UCP3 in human cold resistance. Molecular Biology and Evolution, 28, 601-14.

Hanushek, E. A., \& Woessmann, L. (2011). The economics of international differences in educational achievement. In E. A. Hanushek, S. Machin, \& L. Woesmann (Eds.), Handbook of the Economics of Education (Vol. 3, pp. 89-200). Elsevier.

Kaplan, H. (1996). A theory of fertility and parental investment in traditional and modern human societies. American Journal of Physical Anthropology, 101, 91-135.

Kaplan, H. S., \& Robson, A. J. (2009). We age because we grow. Proceedings of the Royal Society B: Biological Sciences, 276(1663), 1837-1844.

Katzmarzyk, P. T., \& Leonard, W. R. (1998). Climatic influences on human body size and proportions: Ecological adaptations and secular trends. American Journal of Physical Anthropology, 106, 483-503.

Kelly, M., Mokyr, J., \& O'Grada, C. (2015). Roots of the industrial revolution. University of Warwick, Working Paper No. 248.

Kleiber, M. (1932). Body size and metabolism. Hilgardia, 6, 315-353.

Kremer, M. (1993). Population growth and technological change: One million B.C. to 1900. Quarterly Journal of Economics, 108, 681-716.

Krueger, A. B., \& Lindahl, M. (2001). Education for growth: Why and for whom? Journal of Economic Literature, 39(4), 1101-1136.

Lagerlöf, N. (2006). The Galor-Weil model revisited: A quantitative exercise. Review of Economic Dynamics, 9, 116-142.

Lagerlöf, N. P. (2007). Long-run trends in human body mass. Macroeconomic Dynamics, 11(3), 367-387.

Litina, A. (2016). Natural land productivity, cooperation and comparative development. Journal of Economic Growth, 21, 351-408.

Lucas, R. E., Jr. (2002). Lectures on economic growth. Harvard University Press.

Lucas, R. E. (2009). Trade and the diffusion of the industrial revolution. American Economic Journal: Macroeconomics, 1(1), 1-25.

Luzzatto, G. (1948). Storia Economica dell'Eta Moderna e Contemporanea (Vol. 2). Cedam.

Madsen, J. B. (2007). Technology spillover through trade and TFP convergence: 135 years of evidence for the OECD countries. Journal of International Economics, 72(2), 464-480.

Madsen, J. B., Robertson, P. E., \& Ye, L. (2019). Malthus was right: Explaining a millennium of stagnation. European Economic Review, 118, 51-68.

Madsen, J. B., \& Strulik, H. (2020). Testing unified growth theory: Technological progress and the child quantity-quality tradeoff. University of Goettingen, CEGE Discussion Paper 393.

Malanima, P. (1998). Italian cities 1300-1800. A quantitative approach. Rivista di Storia Economica, 14(2), 91-126.

Markovic, G., \& Jaric, S. (2004). Movement performance and body size: The relationship for different groups of tests. European Journal of Applied Physiology, 92, 139-49.

Michalopoulos, S. (2012). The origins of ethnolinguistic diversity. American Economic Review, 102(4), 1508-39.

Michalopoulos, S., \& Papaioannou, E. (2018). Spatial patterns of development: A meso approach. Annual Review of Economics, 10, 383-410.

Murray, D. R., \& Schaller, M. (2010). Historical prevalence of infectious diseases within 230 geopolitical regions: A tool for investigating origins of culture. Journal of Cross-Cultural Psychology, 41(1), 99-108.

NCD Risk Factor Collaboration (NCD-RisC). (2016). A century of trends in adult human height. eLife, 5, e13410. https://doi.org/10.7554/eLife.13410.

Nunn, N., \& Puga, D. (2012). Ruggedness: The blessing of bad geography in Africa. Review of Economics and Statistics, 94(1), 20-36. 
Olsson, O., \& Paik, C. (2016). Long-run cultural divergence: Evidence from the neolithic. Journal of Development Economics, 122, 197-213.

Olsson, O., \& Paik, C. (2020). A western reversal since the Neolithic? The long-run impact of early agriculture. Journal of Economic History, 80(1), 100-135.

Prentice, A. M., \& Whitehead, R. G. (1987). The energetics of human reproduction. Symposia of the Zoological Society of London, 75, 275-304.

Putterman, L., \& Weil, D. N. (2010). Post-1500 population flows and the long run determinants of economic growth and inequality. Quarterly Journal of Economics, 125, 1627-82.

Reher, D. S. (2004). The demographic transition revisited as a global process. Population Space and Place, $10,19-42$.

Robson, A. J. (2010). A bioeconomic view of the Neolithic transition to agriculture. Canadian Journal of Economics, 43(1), 280-300.

Ruff, C. B. (1994). Morphological adaptation to climate in modern and fossil hominids. Yearbook of Physical Anthropology, 37, 65-107.

Sadurskis, A., Kabir, N., Wager, J., \& Forsum, E. (1988). Energy metabolism, body composition, and milk production in healthy Swedish women during lactation. American Journal of Clinical Nutrition, 48(1), 44-49.

Silventoinen, K. (2003). Determinants of variation in adult body height. Journal of Biosocial Science, 35 , 263-285.

Stinson, S. (1990). Variation in body size and shape among South American Indians. American Journal of Human Biology, 2, 37-51.

Strulik, H., \& Weisdorf, J. (2008). Population, food, and knowledge: A simple unified growth theory. Journal of Economic Growth, 13, 195-216.

Strulik, H., \& Weisdorf, J. (2014). How child costs and survival shaped the industrial revolution and the demographic transition. Macroeconomic Dynamics, 18(1), 114-144.

Tilkens, M. J., Wall-Scheffler, C., Weaver, T. D., \& Steudel-Numbers, K. (2007). The effects of body proportions on thermoregulation: An experimental assessment of Allen's rule. Journal of human evolution, 53(3), 286-291.

Walker, R., Gurven, M., Burger, O., \& Hamilton, M. J. (2008). The trade-off between number and size of offspring in humans and other primates. Proceedings of the Royal Society, 275, 827-33.

West, G. B., Brown, J. H., \& Enquist, B. J. (2001). A general model of ontogenetic growth. Nature, 413, 628-31.

Publisher's Note Springer Nature remains neutral with regard to jurisdictional claims in published maps and institutional affiliations. 